\title{
Cluster Analysis of Typhoon Tracks. Part II: Large-Scale Circulation and ENSO
}

\author{
Suzana J. Camargo and Andrew W. Robertson \\ International Research Institute for Climate and Society, The Earth Institute at Columbia University, Palisades, New York \\ Scott J. Gaffney and Padhraic Smyth \\ Department of Computer Science, University of California, Irvine, Irvine, California \\ Michael GHIL* \\ Department of Atmospheric and Oceanic Sciences, and Institute for Geophysics and Planetary Physics, University of California, \\ Los Angeles, Los Angeles, California
}

(Manuscript received 6 January 2006, in final form 15 November 2006)

\begin{abstract}
A new probabilistic clustering method, based on a regression mixture model, is used to describe tropical cyclone (TC) propagation in the western North Pacific (WNP). Seven clusters were obtained and described in Part I of this two-part study. In Part II, the present paper, the large-scale patterns of atmospheric circulation and sea surface temperature associated with each of the clusters are investigated, as well as associations with the phase of the El Niño-Southern Oscillation (ENSO). Composite wind field maps over the WNP provide a physically consistent picture of each TC type, and of its seasonality. Anomalous vorticity and outgoing longwave radiation indicate changes in the monsoon trough associated with different types of $\mathrm{TC}$ genesis and trajectory. The steering winds at $500 \mathrm{hPa}$ are more zonal in the straight-moving clusters, with larger meridional components in the recurving ones. Higher values of vertical wind shear in the midlatitudes also accompany the straight-moving tracks, compared to the recurving ones.

The influence of ENSO on TC activity over the WNP is clearly discerned in specific clusters. Two of the seven clusters are typical of El Niño events; their genesis locations are shifted southeastward and they are more intense. The largest cluster is recurving, located northwestward, and occurs more often during La Niña events. Two types of recurving and one of straight-moving tracks occur preferentially when the MaddenJulian oscillation is active over the WNP region.
\end{abstract}

\section{Introduction}

In the first part of this study (Camargo et al. 2007, hereafter Part I), a new probabilistic clustering methodology based on a regression mixture model was applied to the best-track dataset of the Joint Typhoon Warning Center (2005) for 1950-2002. A set of seven cyclone-track clusters were identified over the western

\footnotetext{
* Additional affiliation: Département Terre-AtmosphèreOcéan, and Laboratoire de Météorologie Dynamique (CNRS and IPSL) Ecole Normale Supérieure, Paris, France.

Corresponding author address: Dr. Suzana J. Camargo, International Research Institute for Climate and Society, Monell 225, 61 Route 9W, Palisades, NY 10964-8000.

E-mail: suzana@iri.columbia.edu
}

North Pacific (WNP), three distinct clusters of straightmoving tracks and four of recurving tracks, with distinct landfall probabilities. Intensity and seasonality of the tropical cyclones (TCs), though unknown to the clustering model, were both found to be highly stratified by the clusters.

The genesis, trajectories, and other characteristics of TCs over the WNP are known to be strongly affected by the large-scale environment and by the El NiñoSouthern Oscillation (ENSO). Indeed, previous studies have capitalized on the relationship between TCs and large-scale circulation anomalies to define modes of TC variability (Harr and Elsberry 1995a). In Part II of this study, we analyze associations between the clusters identified in Part I, the large-scale atmospheric circulation anomalies, and ENSO. Our goals are 1) to determine the physical consistency of the TC clusters; 2) to

DOI: 10.1175/JCLI4203.1

(C) 2007 American Meteorological Society 
characterize the patterns of atmospheric variability over the WNP that accompany different modes of TC behavior; and 3) to isolate potentially predictable components associated with these modes and ENSO.

During summer and early fall, monsoonal southwesterly winds extend eastward at low levels from Asia and carry moisture into the equatorial WNP. These westerlies meet moist low-latitude easterlies over the western North Pacific and form a confluence zone that is conducive to convection (e.g., Holland 1995) and TC formation (Briegel and Frank 1997; Lander 1996; Ritchie and Holland 1999). Easterly waves do not penetrate very far into the monsoonal westerlies: they tend to slow down and turn poleward, leading to accumulation of wave energy in the confluence region (Holland 1995). This interaction can potentially lead to the transformation of these waves into cyclones. Another mechanism of TC formation is the preconditioning of the environment in the wake of a previous cyclone (Frank 1982; Holland 1995; Sobel and Bretherton 1999; Kuo et al. 2001; Li et al. 2003).

The waves affecting the WNP span a wide range of spatial and temporal scales (Holland 1995; Sobel and Bretherton 1999; Kuo et al. 2001; Li et al. 2003). They include the large-scale, eastward-moving, 30-60-day Madden-Julian oscillation (MJO; Madden and Julian 1972); the convectively coupled $N=1$ equatorial Rossby waves (Wheeler and Kiladis 1999); westwardmoving easterly waves that propagate in the trade wind belt of the central Pacific (Reed and Recker 1971; Lau and Lau 1990) and have a characteristic period of 6-9 days; and mixed Rossby-gravity equatorial waves, with a spectral peak at 4-5 days (Itoh and Ghil 1988; Liebmann and Hendon 1990; Dickinson and Molinari 2002). The monsoonal flow often exhibits a life cycle of several weeks (Holland 1995), connected to the MJO, which may thus cause TC tracks to vary intraseasonally as well.

Another important feature of the low-level circulation of the WNP is the subtropical anticyclone, which separates the near-equatorial confluence zone from the midlatitude westerlies. It is well known that TCs usually do not move into the center of the subtropical high, so the latter's location and intensity will influence TC trajectories (Harr and Elsberry 1995a). In the upper troposphere, the anticyclone is more diffuse (Holland 1995), with extensive equatorial easterlies. Tropical upper-tropospheric troughs (TUTTs) can cause changes in cyclone development and tracks (e.g., Sadler 1978; Montgomery and Farrell 1993; Ferreira and Schubert 1999). Sadler (1978) identified the presence of a TUTT as conducive to cyclogenesis in the WNP, while Fer- reira and Schubert (1999) discussed the formation of TUTT cells east of the TCs.

The relationship of ENSO and the total number of cyclones in the WNP has been investigated by several authors (e.g., Atkinson 1977; Chan 1985; Lander 1994a; Chan 2000) with varying results, due to differences in data and techniques used in these studies. In a recent study, Wang and Chan (2002) observed an increase in the number of TCs in that basin during strong El Niño events.

Other studies have identified an important ENSO impact on TC genesis location over the WNP (Pan 1982; Chan 1985; Chen et al. 1998; Wang and Chan 2002; Chia and Ropelewski 2002), with a displacement of the mean cyclone genesis region to the southeast (northwest) during El Niño (EN) [La Niña (LN)] years, respectively. This displacement is known to lead to different track characteristics as well. There is an enhanced tendency of the cyclones in EN years to recurve northeastward and reach more northward latitudes (Wang and Chan 2002). In EN years the cyclones also have a tendency to have longer lifetimes than during LN years (Wang and Chan 2002), to be more intense (Camargo and Sobel 2005), and to form in greater numbers over the central Pacific region (Chu and Wang 1997; Clark and Chu 2002); some of the latter then move into the WNP. Wu and Wang (2004) discussed the anomalous large-scale winds associated with different ENSO phases, consistent with the different track types. Sobel and Camargo (2005) argued that WNP cyclones could play an active role in the development of EN events.

In this paper, we stratify the influence of ENSO phases on cyclones by examining the interannual variability of each TC cluster's frequency of occurrence. We show that the ENSO dependency is specific to particular clusters, thus confirming and expanding Wang and Chan's (2002) results, and that the EN track types that dominate in EN versus LN years are well separated from the others. The fact that different track types prevail during warm versus cold events is important because it leads to different regions of landfall. Differences in landfall patterns in different regions of Asia during ENSO cycles have been discussed in several studies (e.g., Saunders et al. 2000; Elsner and Liu 2003; $\mathrm{Wu}$ et al. 2004). Here we show the anomalous largescale atmospheric circulation patterns associated with the landfall distributions constructed for each cluster, including relationships with ENSO.

While ENSO strongly influences the interannual variability of TC tracks in the WNP, other factors may also be important, such as the MJO (Liebmann et al. 1994; Sobel and Maloney 2000), stratospheric quasi- 
biennial oscillation (Chan 1995), TUTTs (Sadler 1978), and associations with the Indian summer monsoon (Kumar and Krishnan 2005). Of these, we discuss here MJO effects. Variability on decadal or longer time scales in typhoon activity, tracks, and landfall have been discussed in various studies (Chan and Shi 2000; Chu 2002; Ho et al. 2004) but are not considered in the present analysis.

The datasets and methods are described briefly in section 2. In section 3 we construct composites of atmospheric circulation patterns and sea surface temperature (SST) fields for each cluster. The relationship with ENSO and MJO is investigated in section 4. A summary and a discussion are presented in section 5 .

\section{Data and methods}

The cyclone data are based on the Joint Typhoon Warning Center (2007) best-track dataset for the time interval 1950-2002, as used in Part I. Tropical depressions are present in this dataset, but only TCs with tropical storm intensity or higher are included in our analysis. The clustering methodology was applied to a total of 1393 TC tracks, as described in detail in Part I. Further methodological details can be found in Gaffney (2004) and Gaffney et al. (2007), where the method was applied to North Atlantic extratropical cyclones.

Each track is assigned to one of seven clusters. To analyze the large-scale environment associated with each cluster, we use several standard datasets: weekly SST fields, available from November 1981 (Reynolds et al. 2002), daily National Oceanographic and Atmospheric Administration (NOAA) outgoing longwave radiation (OLR) available continuously since 1979 (Liebmann and Smith 1996), and several meteorological variables from the National Centers for Environmental Prediction-National Center for Atmospheric Research (NCEP-NCAR) reanalysis (Kalnay et al. 1996), since 1950. In each case, we use the entire data record available to us. Anomalies are defined relative to the 1971-2000 climatology for the reanalysis and Reynolds datasets, and relative to 1979-2002 for NOAA OLR. Daily climatologies, obtained using 3-day running means, are used for atmospheric variables, and weekly values for SST.

The statistical significance of the resulting composites was determined using a Monte Carlo test, described in the appendix. The results were verified in several selected cases using a hypergeometric statistical test, as described in Mason and Goddard (2001), which was found to give very similar results at the $95 \%$ significance level.

The monthly SST index for the Niño-3.4 area $\left(5^{\circ} \mathrm{S}-\right.$ $5^{\circ} \mathrm{N} ; 170^{\circ}-120^{\circ} \mathrm{W}$; Barnston et al. 1997) was used to define the phase of ENSO, obtained from the Climate Prediction Center (CPC) Web site (CPC 2007). We define $\mathrm{EN}$ and $\mathrm{LN}$ years according to the value of the Niño-3.4 index averaged over the months of JulyOctober (JASO), spanning the peak of the typhoon season. The 13 yr (approximately $25 \%$ of the $53-\mathrm{yr}$ period) with the largest and smallest values of Niño-3.4 in the period 1950-2002 are defined as EN and LN years, respectively; the remaining $27 \mathrm{yr}$ are classified as neutral years. The EN and LN years defined using our percentile method correspond to the Northern Hemisphere summers before the peaks of the ENSO events and correspond well to the ENSO events obtained using more traditional definitions; see for instance, Trenberth (1997), as discussed by Goddard and Dilley (2005).

\section{TC clusters and the large-scale circulation}

We constructed composites of large-scale circulation patterns associated with each cluster by compositing the days that correspond to either the first position or the maximum intensity of each cyclone. The results are very similar in either case, so we show here only the composites for the first position. The rationale for choosing the first position is the potential usage of these patterns in tracks and landfall forecasts, once the genesis position of a cyclone is known. Besides, the largescale circulation patterns that control genesis and track type are not independent from each other, since they are associated with different positions and intensities of the monsoon trough and subtropical ridge (Harr and Elsberry 1991). In the case of the steering winds, the composites were constructed using all the days during which a TC was active. The number of TCs included in each composite varies by cluster, and according to the length of the available dataset for each variable (OLR, SST, wind fields, etc).

\section{a. Steering winds}

The movement of cyclones is largely determined by the ambient flow, the so-called large-scale steering winds. The midtropospheric levels (700 and $500 \mathrm{hPa}$ ) have been found to have the best correlation with TC direction and speed (Chan and Gray 1982). The steering is due to the advection of concentrated relative vorticity associated with the cyclone by the large-scale environmental winds (Wu and Wang 2004). A highly idealized form of this steering can be found in the motion of point or Rankine vortices in a two-dimensional velocity field (von Helmholtz 1858; Aref 1983; Ide and Ghil 

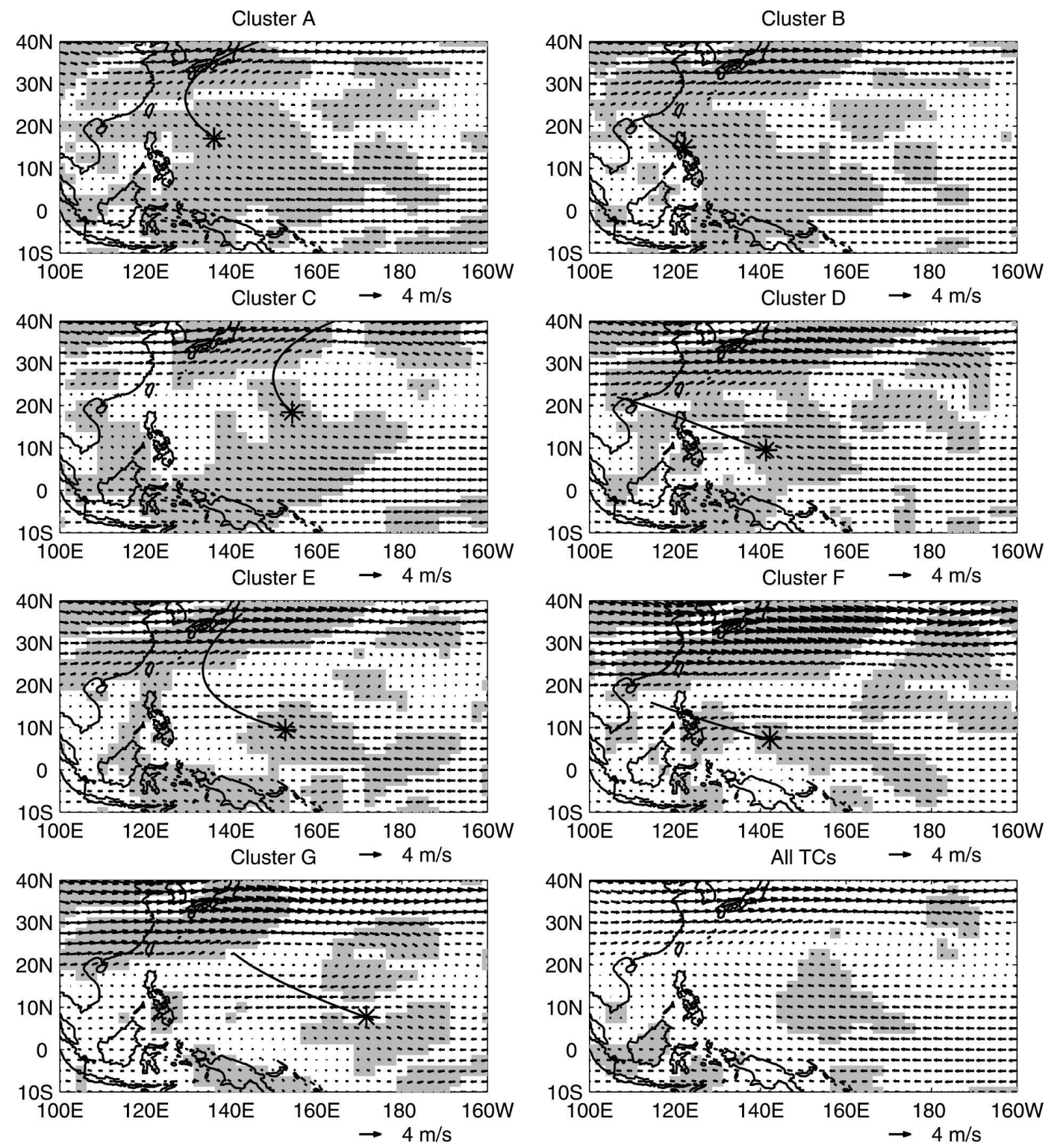

FIG. 1. Daily wind $(500 \mathrm{hPa})$ composites, for the cyclones (TCs) in each cluster and for all TCs during the period 1950-2002. Shaded regions are statistically significant. The composites are based on all days during which a TC was active. Also shown are the mean regression trajectory (black line) and genesis location (black asterisk) for each cluster.

1997a,b). Other fundamental contributions to cyclone motion are the "beta drift," due to the advection of planetary vorticity by the TC circulation, and nonlinear interactions with the large-scale winds and planetaryvorticity gradient (Fioriono and Elsberry 1989; Wang and Holland 1996). These contributions tend to cause a net drift to the northwest, relative to the steering winds, especially in the case of weak ambient flows (Wang and Li 1992; Wang and Holland 1996; Carr and Elsberry 1990; Franklin et al. 1996). Various theoretical and observational studies (e.g., Emanuel 1991; Wu and Eman- uel 1995; Chan 2005) have also discussed the effects of a nonuniform background, interaction between cyclones and the monsoonal flow, and other issues.

We show in Figs. 1 and 2 wind and anomalous winds composites at $500 \mathrm{hPa}$, over all days of each trajectory; the patterns for $700 \mathrm{hPa}$ (not shown) are very similar. In each cluster the mean regression trajectory is clearly consistent with the composite wind fields, indicating the dominating influence on the former. In all the clusters, the northwestward drift is evident, either throughout the trajectory (for the straight movers in clusters B, D, 

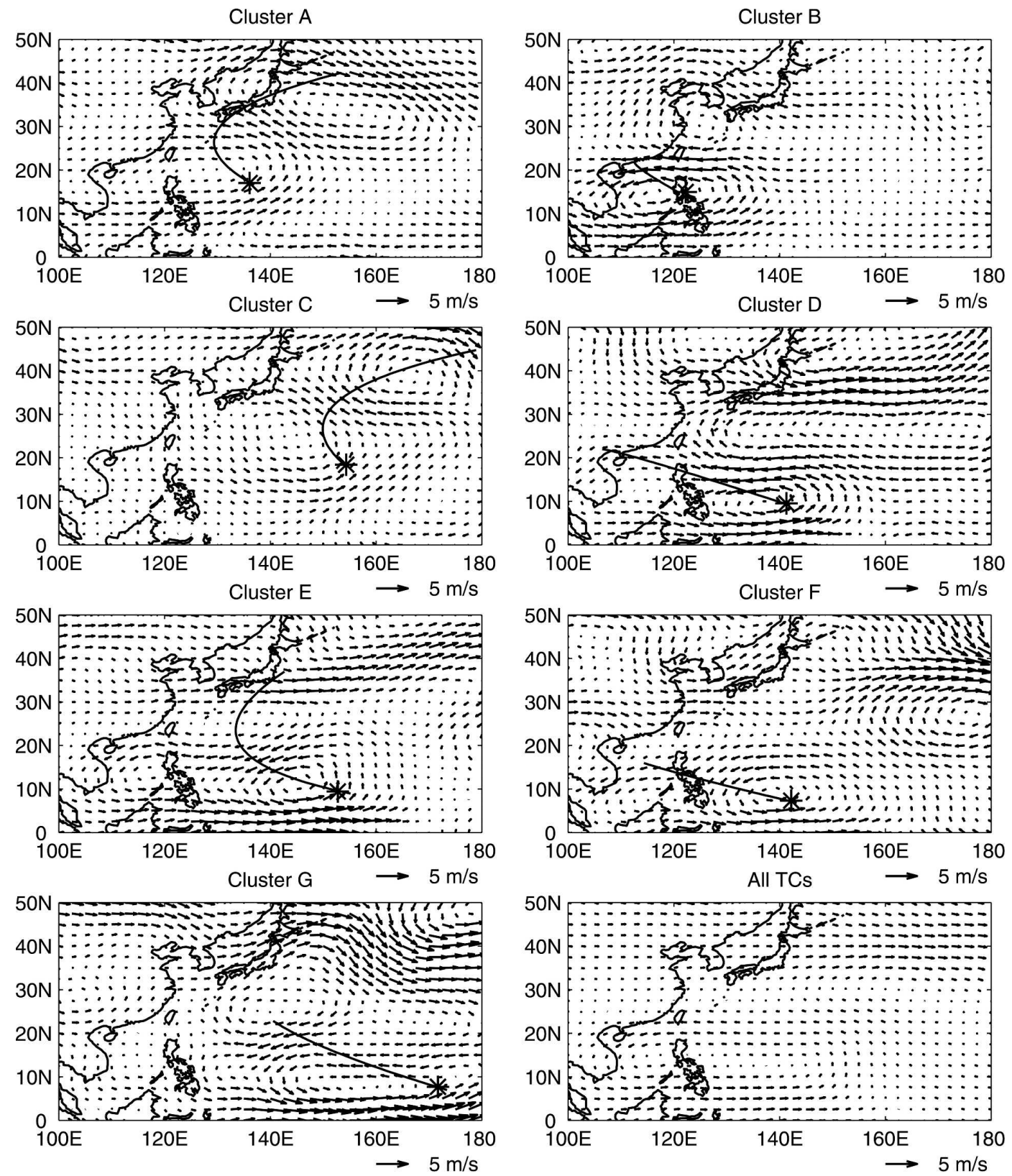

FIG. 2. Composites of daily anomalous wind fields at $500 \mathrm{hPa}$ for the cyclones in each cluster and for all TCs during the period 1950-2002. Also shown are the mean regression trajectory (gray line) and genesis location (gray asterisk) for each cluster.

$\mathrm{F}$, and $\mathrm{G}$ ) or at least during its early part (for the recurvers in clusters $\mathrm{A}, \mathrm{C}$, and $\mathrm{E}$ ).

The recurving clusters (A, C, and $\mathrm{E})$ are generated in a region of southeasterly flow, with the recurving occurring at the latitudes between $20^{\circ}$ and $30^{\circ} \mathrm{N}$, where the trade easterlies change to subtropical westerlies that are not reached by the straight movers. Although there is a good deal of within-cluster spread about the mean regression trajectory (Fig. 5 of Part I), the latter have similar shapes, and the main difference between these three clusters is largely in the different mean genesis locations.

The reasons why the straight movers hit land (clusters $\mathrm{B}$ and $\mathrm{D}$ ) or decay in the latitudes of low surface winds, near $20^{\circ} \mathrm{N}$ (clusters $\mathrm{F}$ and $\mathrm{G}$ ), are more complex and involve genesis position and less northward drift in their early stages. The genesis location of cluster B, a straight-moving cluster, is close to the Asian coast, with 

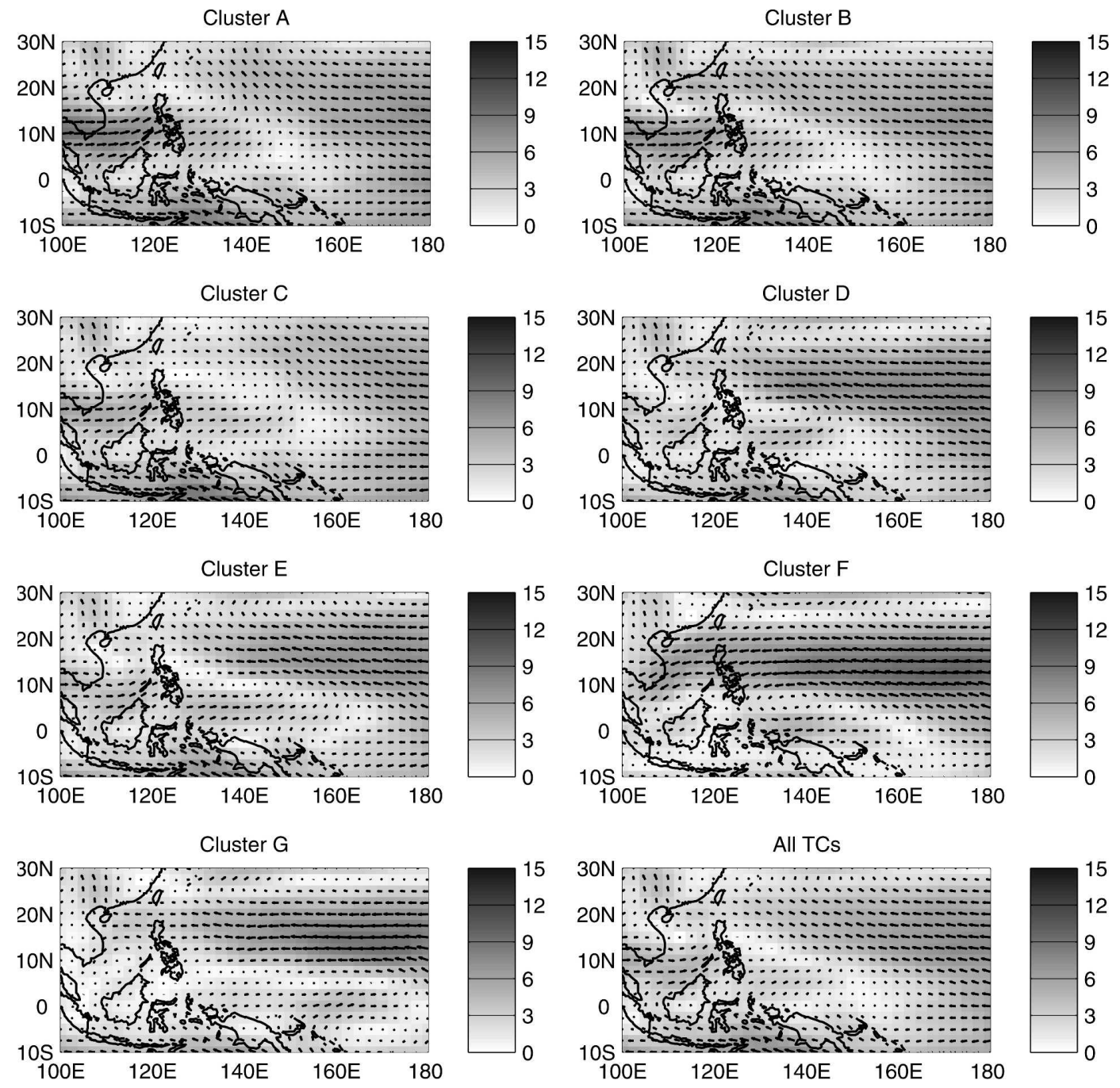

FIG. 3. Composites of daily total winds at $850 \mathrm{hPa}$ for the cyclones in each cluster and for all TCs during the period 1950-2002, based on genesis days only. The magnitude of the winds is indicated in the grayscale $\left(\mathrm{m} \mathrm{s}^{-1}\right)$.

most TCs over the South China Sea and Philippine Sea. The other straight-moving clusters (D, F, and G) have mean genesis locations in regions of easterly flow and strong easterly anomalies (Fig. 2) that are typical of straight-moving storms, as discussed in Harr and Elsberry (1991). These anomalous easterlies are part of the southern part of a strong or elongated subtropical ridge (Fig. 2). It is important to note, though, that the total wind field for cluster $G$ is not statistically significant at any point during the mean track (Fig. 1).

\section{b. Winds, low-level vorticity, and $O L R$}

Composites of the $850-\mathrm{hPa}$ total winds associated with each cluster and over all TCs together are plotted in Fig. 3. Also shown are the anomalous winds and vorticity at $850 \mathrm{hPa}$ in Fig. 4 and anomalous OLR com- posites in Fig. 5. All fields are composites over TC first positions only.

The monsoon trough is a region of low-level pressure and convergence between the lower troposphere characterized by the presence of equatorial southwesterlies on the equatorial side and the trade wind easterlies. The monsoon trough climatological position emerges from Asia around $20^{\circ} \mathrm{N}$ and extends southeastward toward the equatorial western North Pacific with a terminus around $13^{\circ} \mathrm{N}, 145^{\circ} \mathrm{E}$ (Fig. 1a in Lander 1996). The monsoon trough exhibits substantial migrations and major changes of shape and orientation (Fig. 2 in Lander 1996).

The east-west-oriented monsoon trough across the Philippines is clearly visible in the all-TC composites (bottom-right panels) as a region of cyclonic anomalies 

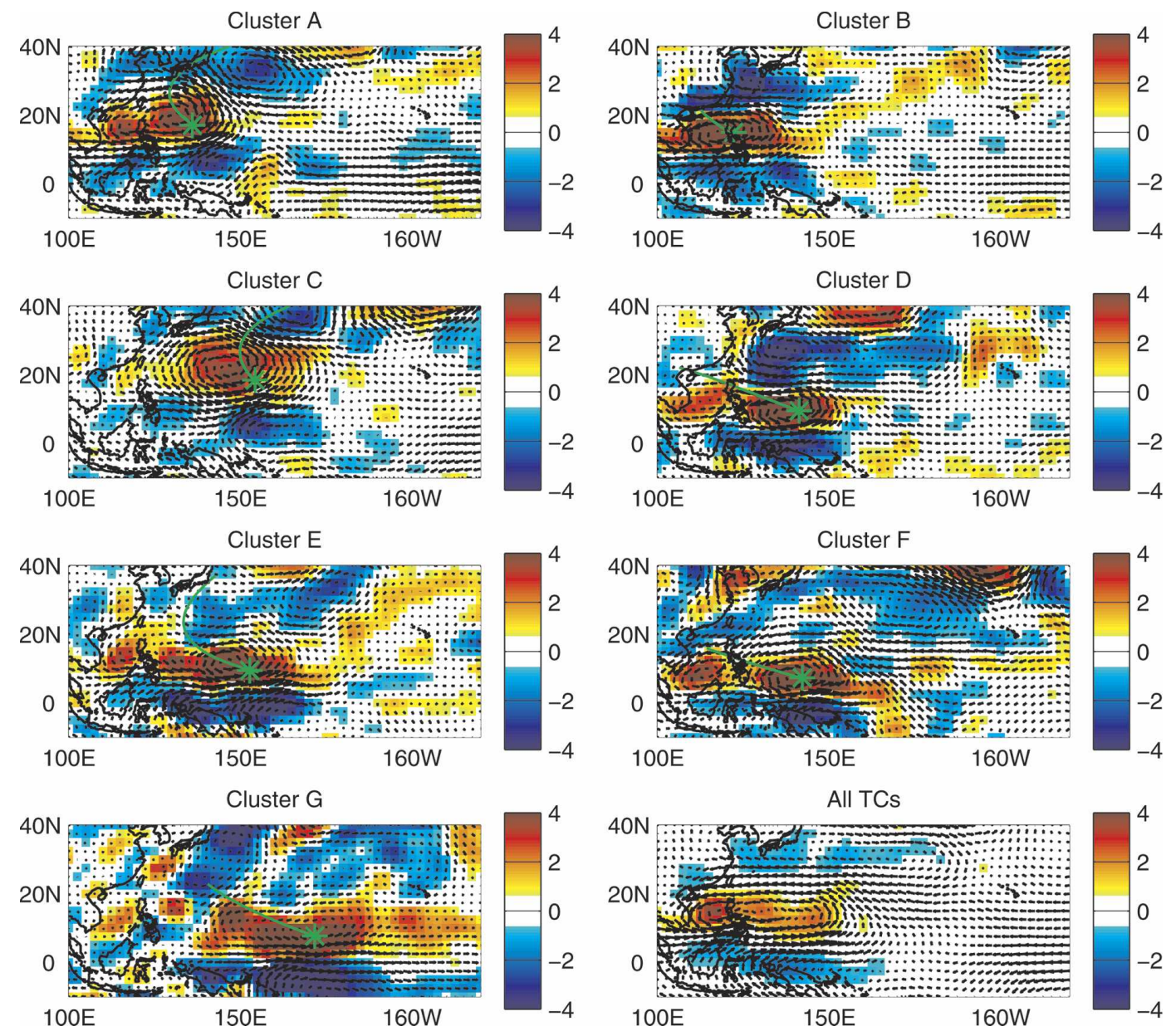

FIG. 4. Composites of daily anomalous winds at $850 \mathrm{hPa}$ and vorticity at $850 \mathrm{hPa}\left(\times 10^{-6} \mathrm{~s}^{-1}\right)$ for the cyclones in each cluster and for all TCs during the same period, based on genesis days only. Only statistically significant regions of the vorticity composites are shown (in color). Also shown are the mean regression trajectories (green) and genesis locations (green asterisk) for each cluster.

(Fig. 4g) and negative OLR (Fig. 5g) with the southwesterlies to its equatorial side (Fig. 3g). The circulation anomalies are relatively deep, extending into the midtroposphere, with cross-equatorial flow at low levels. These cyclonic anomalies represent an east- and northward extension of the seasonal monsoon trough, showing that TCs have a strong relationship with the monsoon trough over the WNP. There is also a region of anticyclonic subtropical anomalies situated to the north, which represents a westward extension of the climatological subtropical anticyclone in the WNP.

The location and size of the cyclonic anomaly is cluster dependent, so that the monsoon trough characteristics differ from cluster to cluster. Much of these between-cluster differences reflect the relationships of the TCs themselves (cf. the cluster genesis locations in Fig. 7 of Part I) and the monsoon trough, confirmed by the significant values $(95 \%$ level) for the pattern correla- tions between the OLR anomalies and genesis density for each cluster (Table 1). The anomalous cyclonic circulation of cluster A contributes to the strengthening of the monsoon trough, while that of cluster $\mathrm{C}$, shifted to the northeast, contributes to its weakening. The enhanced equatorial westerlies of cluster $\mathrm{E}$ point to a more elongated monsoon trough. The anticyclonic anomalies to the north and south of the anomalous monsoon trough are particularly pronounced in several of the clusters. To the north, these anomalies contribute to changes in the strength and pattern of the subtropical ridge. In the case of cluster $\mathrm{B}$, for instance, the TCrelated anticyclonic anomalies occur over the Asian coast and are thus separated from the main subtropical ridge.

Rossby wave-like structures are present to the southeast of the main cyclonic anomaly in clusters $\mathrm{A}$ and $\mathrm{C}$ (see Fig. 4); these waves are similar to the disturbances 

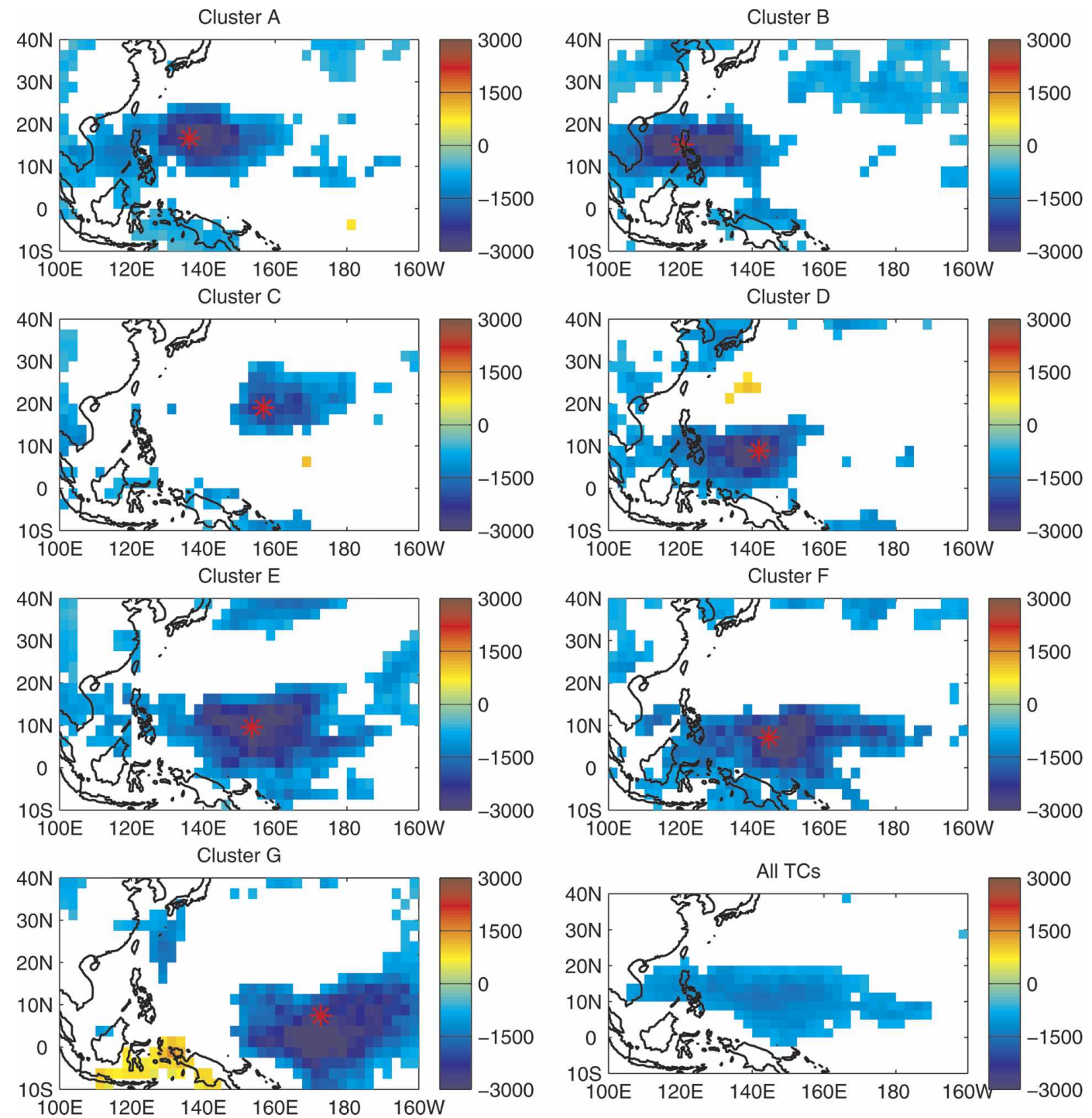

FIG. 5. Composites of daily anomalous OLR for the cyclones in each cluster and for all TCs during the period 1979-2002, based on genesis days only. Only statistically significant regions of the OLR anomalous composites are shown (in color); color bar is in $\times 10^{3} \mathrm{~W} \mathrm{~m}^{-2}$. The mean genesis location (red asterisk) for each cluster is also shown.

discussed by Sobel and Bretherton (1999), Kuo et al. (2001), and Li et al. (2003). While a TC moves northwestward due to mean flow steering and beta drift, it emits Rossby wave energy southeastward, forming a synoptic-scale wave train with alternating anticyclonic

TABLE 1. Correlations (significant at the 95\% level) between the OLR anomalies (with the sign changed) and the genesis density for each cluster.

\begin{tabular}{cccccccc}
\hline \hline Cluster & A & B & C & D & E & F & G \\
\hline Correlation & 0.50 & 0.44 & 0.27 & 0.39 & 0.43 & 0.36 & 0.33 \\
\hline
\end{tabular}

and cyclonic vorticity perturbations (Holland 1995). A TC can generate barotropic Rossby waves at $850 \mathrm{hPa}$ in the tropical easterlies and through wave accumulation mechanisms trigger initial development of subsequent TCs. One essential feature for this mechanism is the presence of a monsoon confluence zone in the WNP with opposing low-level zonal flow (monsoonal westerlies meeting trade easterlies), which could lead to wave accumulation (Sobel and Bretherton 1999; Kuo et al. 2001). Although our wind cluster composites did reveal Rossby wave trains, we did not identify westwardmoving propagating anomalies in the low-level wind composites. 
Cluster A

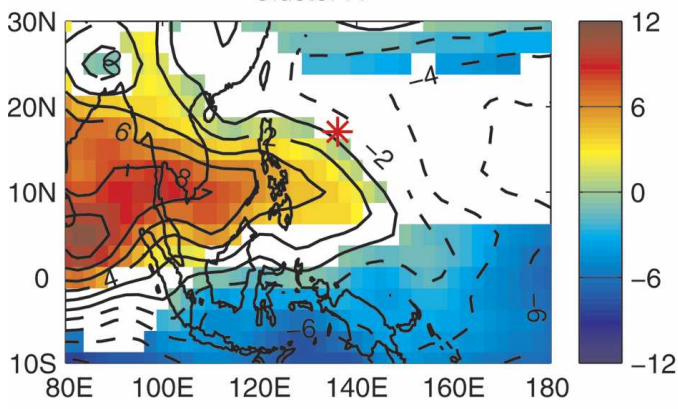

Cluster C

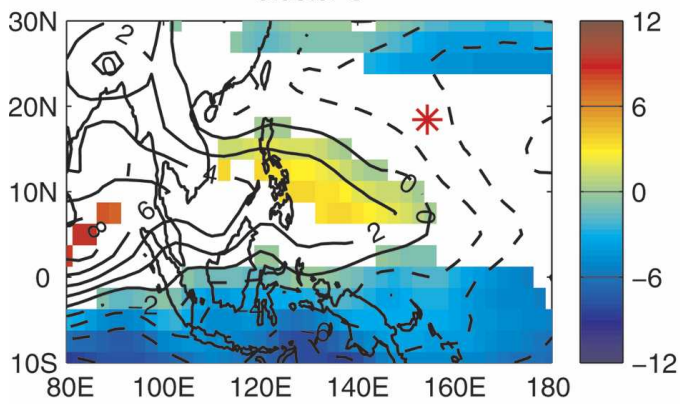

Cluster E

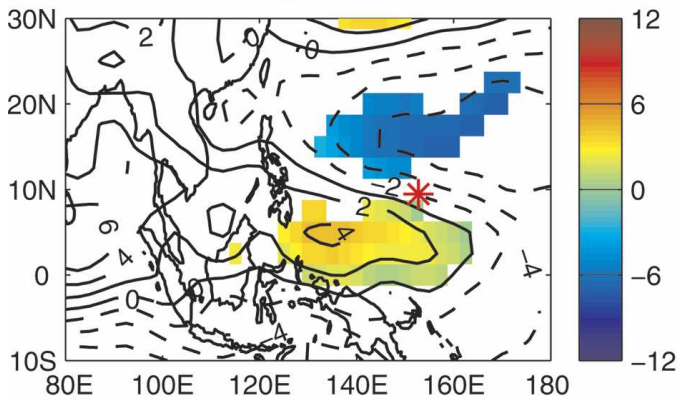

Cluster G

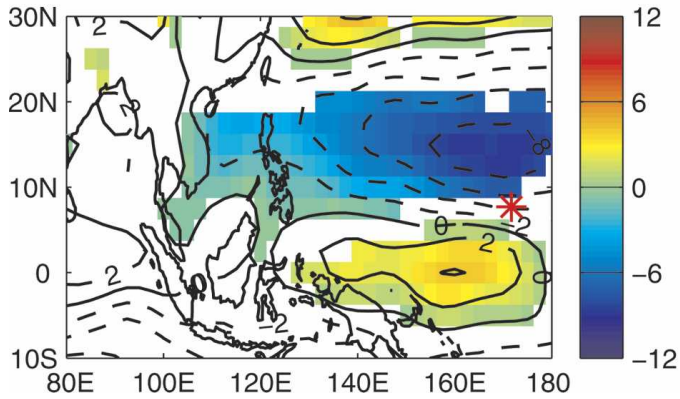

Cluster B

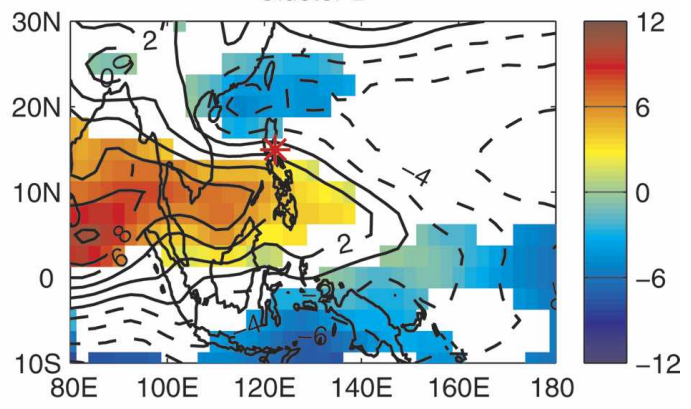

Cluster D

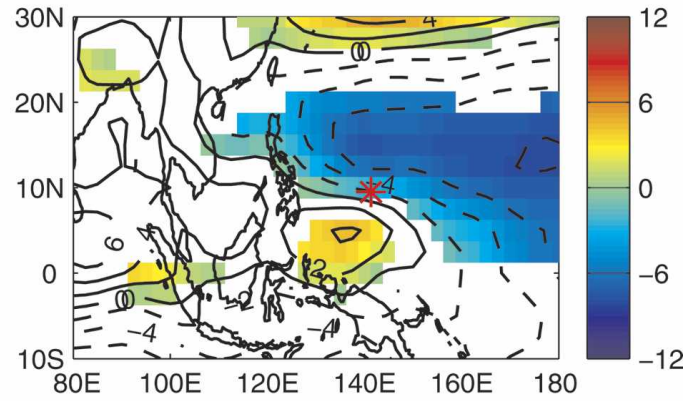

Cluster $\mathrm{F}$

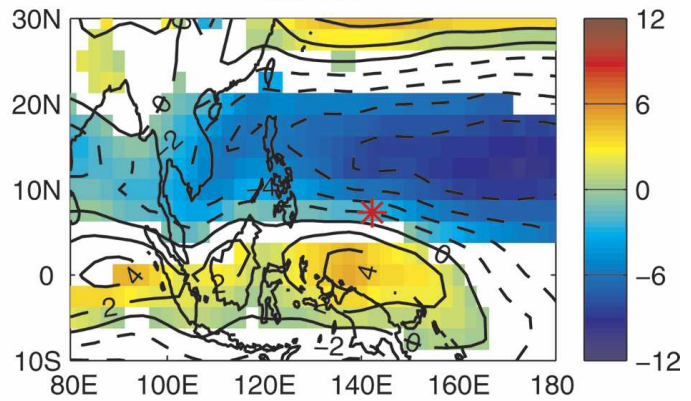

All TCs

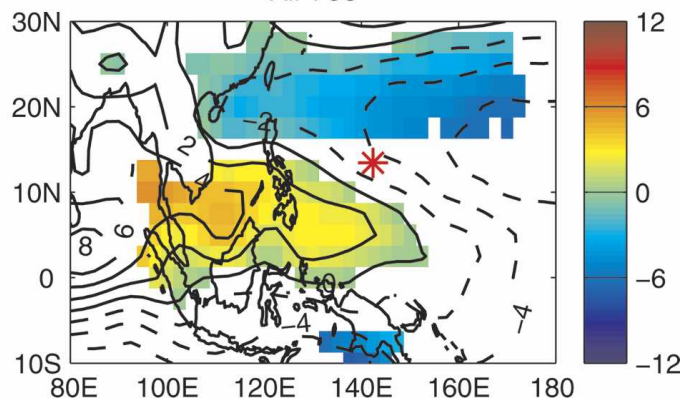

FIG. 6. Composites of daily zonal winds at $850 \mathrm{hPa}$ (contours and colors) for the cyclones in each cluster and for all TCs in the period 1950-2002, based on genesis days only. Colored regions are statistically significant. Also shown is the mean genesis location for the different clusters (red asterisk).

c. Low-level zonal winds, sea level pressure, and wind shear

Differences in the monsoon trough and trade wind regime between the clusters are highlighted in Fig. 6, which shows composites of the zonal wind. Ritchie and
Holland (1999) identified two major flow features, which were directly associated with $70 \%$ of all TC genesis: (i) the monsoon shear line (zero contour line between zonal westerlies and easterlies); and (ii) the confluence region between easterly and westerly flow at the eastern extremity of the monsoon trough. In our 

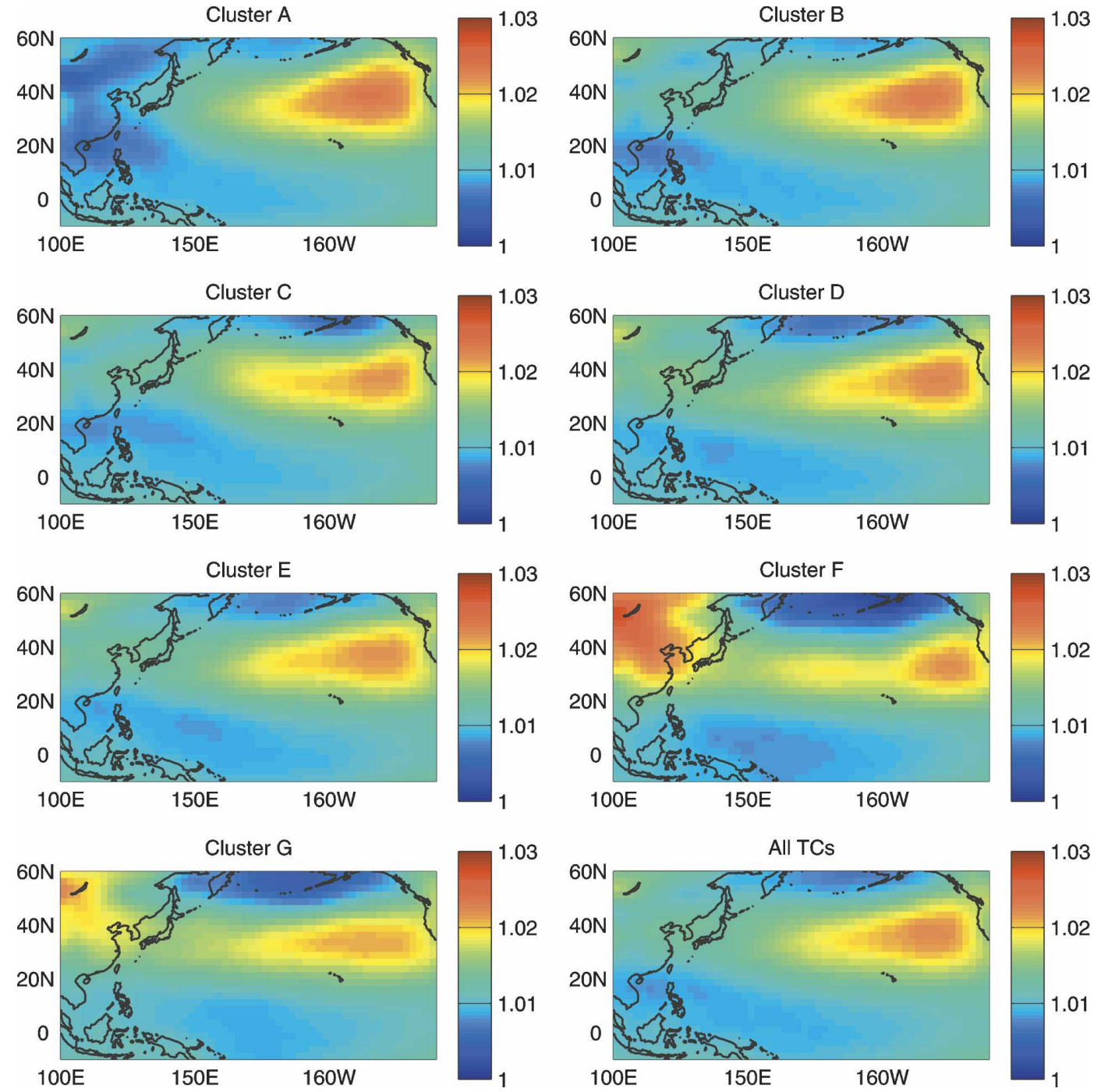

FIG. 7. Composites of daily sea level pressure for all TCs in the period 1950-2002, based on genesis days only. Color bar is in $\mathrm{hPa}$.

composites, the mean genesis location (red asterisk in the figure) is located west of the confluence of the westerly monsoon winds and the easterly trade winds for all the clusters, very near the monsoon shear line. The location of the mean genesis west of the confluence region in all cluster composites points to the importance of this wind pattern for typhoon genesis and is in agreement with the analysis of Ritchie and Holland (1999)

None of these composites show a reverse monsoon trough pattern (Lander 1996), nor the more rare monsoon gyre pattern (Lander 1994b; Carr and Elsberry 1995; Chen et al. 2004). The fact that these patterns are not present in the composites is probably due to the fact that they do not occur very frequently and therefore these patterns would be smeared out in our composites.
The different locations of the monsoon shear line among the clusters resembles the seasonal migration of the monsoon trough shown in Fig. 2 of Lander (1996).

The sea level pressure (SLP) composites (Fig. 7) indicate the importance of the pattern, strength, and extent of the subtropical high in determining the characteristics of each cluster. The composites show a region of low SLP extending from Southeast Asia through the Philippines in the direction of the equator, associated with the monsoon trough. In clusters $\mathrm{F}$ and $\mathrm{G}$, there is a second high in SLP over the Asian continent.

Anomalies in the vertical wind shear (zonal and meridional) between 200 and $850 \mathrm{hPa}$ are quite different among the clusters, as shown in Fig. 8, for composites of first position. In all clusters, the formation occurs over regions of low values of total wind shear, as expected. 

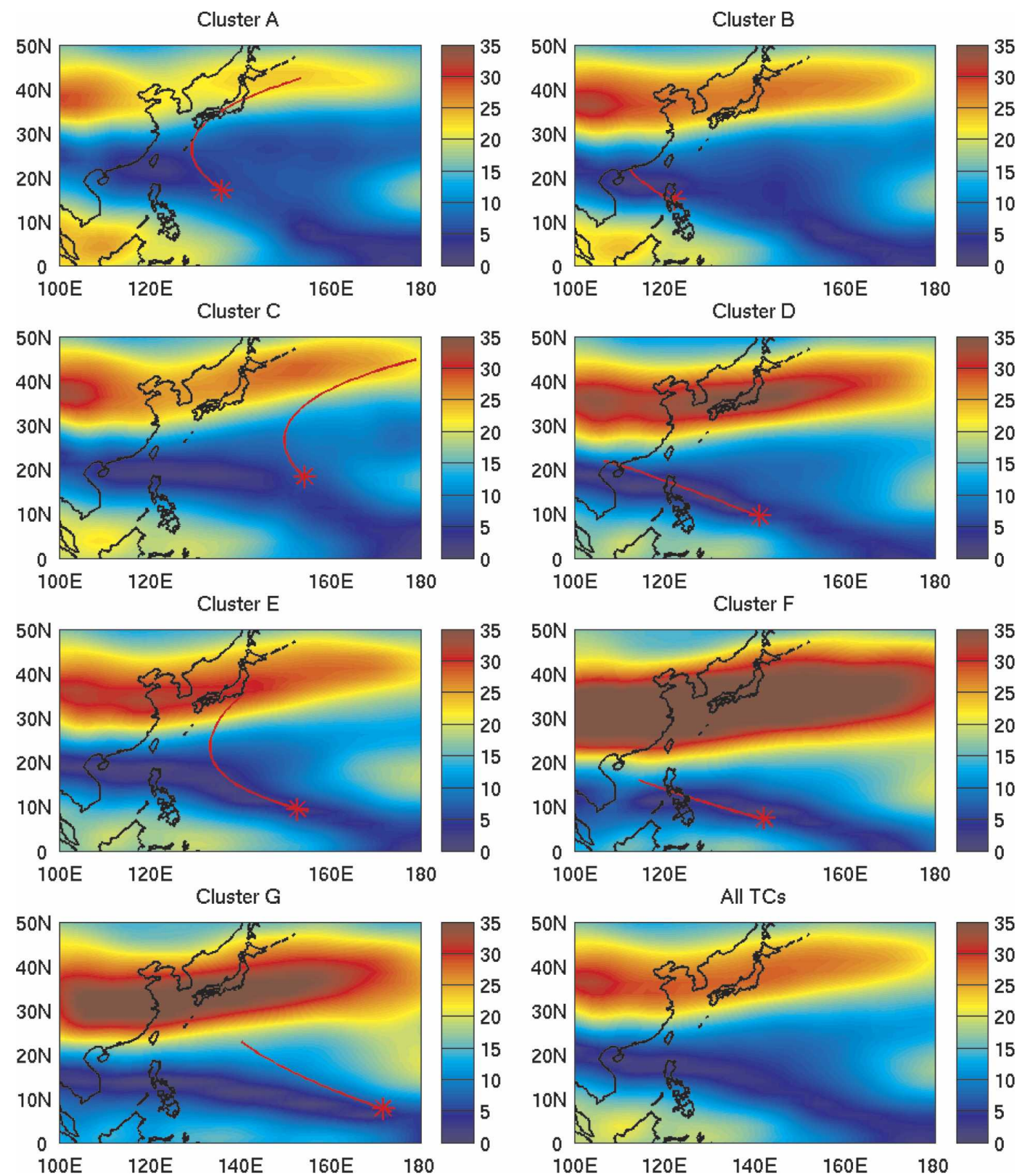

FIG. 8. Composites of daily total vertical wind shear, between 200 and $850 \mathrm{hPa}$, and composites for the cyclones in each cluster and for all TCs in the period 1950-2002, based on genesis days only. Color bar is in m s${ }^{-1}$, for the magnitude of the vector difference between the wind at 200 and $850 \mathrm{hPa}$, at the same horizontal position. Also shown are the mean regression trajectory (red line) and genesis location (red asterisk) for each cluster.

The recurving trajectory clusters tend to have smaller values of wind shear around $40^{\circ} \mathrm{N}$; see, for instance, clusters $\mathrm{A}$ and $\mathrm{C}$ versus $\mathrm{B}$ and $\mathrm{D}$. The straight-moving storms face higher values of wind shear at or near $30^{\circ} \mathrm{N}$, which probably contributes to the fact that those TCs do not recurve. The tracks of the clusters with low values of wind shear in the subtropics seem to follow more closely the large-scale winds (Fig. 1); they follow the latter less closely for the clusters with high wind shear.
For stronger wind shear, the TC movement cannot be explained using a simple barotropic framework, dominated by the beta-drift, and thus a baroclinic theory is necessary (Chan 2005).

\section{d. SST anomalies}

SSTs interact significantly with cyclones, in terms of the impact of warm SSTs on their genesis, as well as of the impact of TCs on the underlying SST through 

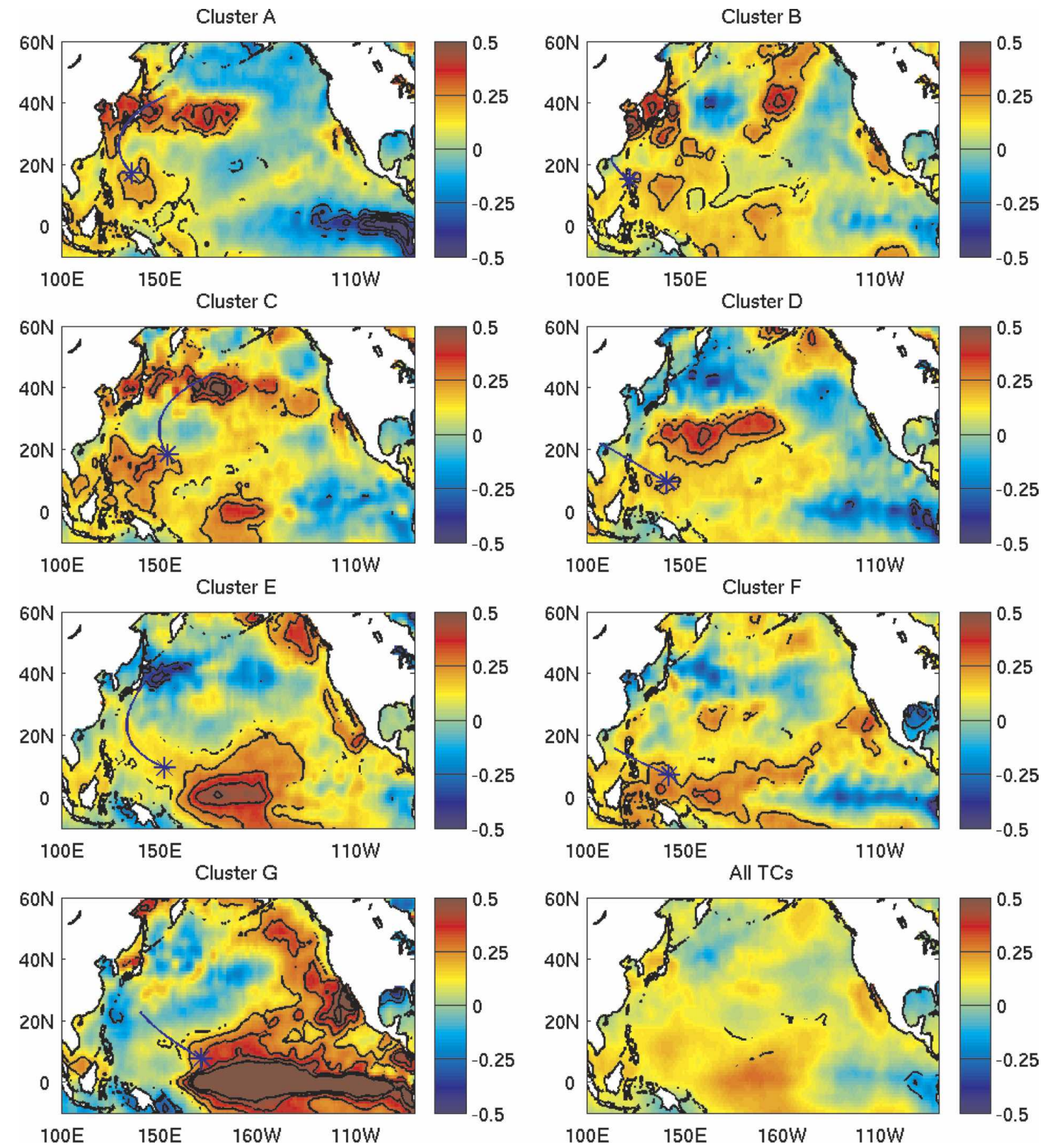

FIG. 9. Composites of weekly SST anomalies for the cyclones in each cluster and for all TCs in the period November 1981 to December 2002; color bar in ${ }^{\circ} \mathrm{C}$. Regions that are statistically significant at the $95 \%$ level are in contours. Also shown are the mean regression trajectory (blue line) and genesis location (blue asterisk) for each cluster.

strong evaporative cooling. At the same time, SSTs can be expected to reveal slow-changing aspects of the large-scale environment, including ENSO.

We constructed, therefore, composites of weekly SST anomalies selecting the week (Wednesday-Tuesday) that was nearest to the TC genesis. The local cooling of SSTs immediately under an individual cyclone can be greater than $5^{\circ} \mathrm{C}$ (Lin et al. 2003), influencing other cyclones on the same path (Brand 1971) or the TC itself (Emanuel 1999). In our SST composites this cooling is not present, probably because the cooling is fairly lo- calized and the TCs in the composites occur at different locations; furthermore, the composites use the SSTs at the time of genesis, when the cooling effect is much weaker than at the cyclones' maximum intensity.

Figure 9 shows the SST anomaly composites. The all-TC anomalies are weakly warm over the central and western equatorial Pacific, but the anomalies generally do not reach the $95 \%$ confidence level. There are, however, regions of highly significant SST anomalies for the individual clusters. The ENSO influence is clearly visible for cluster G, where a typical EN pattern is both 
strong and highly significant. The cluster E composite shows equatorial warming within $20^{\circ}-30^{\circ}$ either side of the date line. Clusters A, D, and F show cold anomalies in the eastern equatorial Pacific, typical of LN conditions, and they are strongest and most significant in cluster A. Similar to the composites for all TCs, clusters $\mathrm{B}$ and $\mathrm{C}$ have a neutral ENSO pattern, with slightly cold anomalies in the eastern tropical Pacific and warm central tropical Pacific SSTs.

Besides the SST anomaly patterns associated with ENSO phases in the tropical Pacific, other SST anomalies are present in the composites. Clusters A and C have strong and very significant warm anomalies in a strip along $40^{\circ} \mathrm{N}$, overlying the Kuroshio Extension; these anomalies extend all the way across the Pacific in cluster C. Cluster B shows warm SST anomalies in the Sea of Japan and the East China Sea, with the warm SST anomalies continuing east of Japan in a curved strip with a second maximum around $\left(40^{\circ} \mathrm{N}, 160^{\circ} \mathrm{W}\right)$. Cluster D also exhibits warmer waters in the western part of the subtropical gyre, around $30^{\circ} \mathrm{N}$.

Though the mean first positions are associated with anomalous warm SSTs for all clusters, they are not necessarily the warmest SST values in the region. The mean first position of cluster A cyclones coincides with a region of warm SST anomalies (east of the Philippines), and in cluster D it is well to the south of the main SST warming. In the case of clusters $E$ and $G$ the first positions are located northwest of the equatorial SST warm anomalies. The negative OLR anomalies (see Fig. 5) appear to be associated with the anomalous warm SSTs as well as with the presence of TCs.

\section{ENSO and MJO phases associated with the clusters}

Some of the cluster composites of atmospheric quantities also exhibit certain characteristics of ENSO phases. For instance, the positive OLR anomaly over the Maritime Continent in cluster G (see Fig. 5) is due to the well-known impact of warm ENSO events, whose modified Walker Cell causes that region to be dry (Ropelewski and Halpern 1987). Clusters E and G also show strong anomalous low-level westerly winds in the western tropical Pacific (see Fig. 4), which likewise characterize the Walker Cell circulation associated with EN events (e.g., Rasmusson and Carpenter 1982). The low-level anomalous easterly winds present in cluster A composites are consistent with the dominance of LN events in this cluster.

In this section we examine various cyclone activity statistics of each cluster and their relationship with
ENSO, including the number of TCs, their intensity, and landfall (Table 2). Figure 10 shows the number of cyclones per year in each cluster, with EN, LN, and neutral years identified. Clusters E and G, especially, show an increase in the number of TCs in the satellite era, suggesting that many TCs went undetected over the tropical ocean in the presatellite era. This is not the case for some of the other clusters, especially clusters $\mathrm{A}, \mathrm{B}$, and $\mathrm{C}$.

In spite of overall changes in TC frequency, clusters $\mathrm{F}$ and $\mathrm{G}$ are noticeably more frequent in EN years, while cluster A occurs more frequently in $\mathrm{LN}$ years. This observation was confirmed by the correlations of these time series with the Niño-3.4 index, shown in Table 3. Both Pearson's and Spearman's rank correlations are significantly positive for clusters $\mathrm{E}$ and $\mathrm{G}$ and negative for cluster $\mathrm{A}$. The number of cyclones in the other clusters are not significantly related to the phase of ENSO. When all the TCs are considered there is no linear relationship between the number of tropical cyclones (NTC) and ENSO.

We analyzed next the relationship between NTC and ENSO phase by season, for 1950-2002 (Table 3); the results for 1970-2002 (not shown) are similar. Cluster A has significant negative correlations from boreal spring [May to July (MJJ, hereafter 3-month periods are denoted by the first letter of each respective month)] to boreal fall (SON). For cluster E, correlations are significantly positive in spring and early summer (MJJ to JAS), while in cluster $G$ this happens in the fall to early winter (SON to NDJ). Interestingly, in clusters B and D correlations with Niño-3.4 are significantly negative only in the late fall/early winter.

The average number of tropical cyclones in $\mathrm{LN}$ is shown in Fig. 11 (top). The tendency to have fewer cyclones in EN years in cluster A and more of them in clusters $\mathrm{E}$ and $\mathrm{G}$ is clear. This is confirmed by Kolmogorov-Smirnov and Monte Carlo tests, which determined that the distributions of NTC per year in EN and LN years for clusters A, E, and G are statistically distinct; this is even true for clusters $\mathrm{E}$ and $\mathrm{G}$ when comparing $\mathrm{LN}$ and neutral years.

\section{a. Tropical cyclone intensity and ENSO}

To determine the relationship between ENSO phase and cyclone intensity for each cluster, the TCs were stratified into three different strengths, aggregating categories from the Saffir-Simpson scale (Saffir 1977; Simpson and Riehl 1981) as follows: tropical storms (TS), typhoons (TY; categories 1-2), and intense typhoons (ITY; categories 3-5). Camargo and Sobel (2005) have shown that in EN years, there is a tendency 


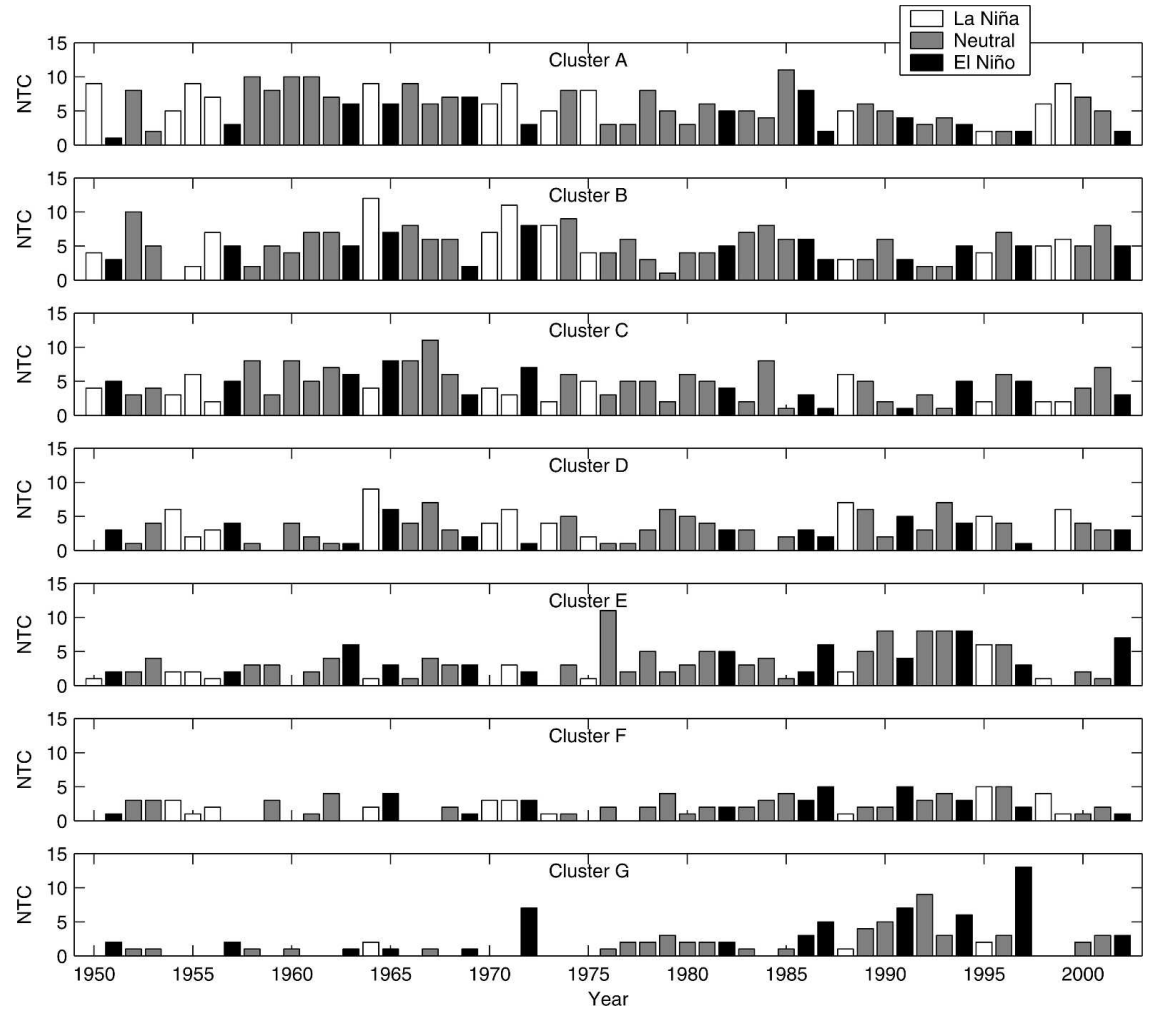

FIG. 10. NTC per year in each cluster in the period 1950-2002.

to have more intense and long-living typhoons, with fewer and short-living TCs in LN years.

Figure 11 shows the mean number of TS, TY, and ITY cyclones in each cluster in LN, neutral, and EN years. While cluster A has fewer cyclones for all three strength levels in EN years, clusters E and G have a much higher ITY number in those years. Interestingly, there is also a noticeable increase in the number of ITYs in cluster C in EN years; a Monte Carlo test (not shown) confirmed the statistical significance of these results.
One of the cyclone activity measures commonly used is the accumulated cyclone energy (ACE; Bell et al. 2000), which combines the number, lifetimes, and intensities of TCs occurring over a given period of time. $\mathrm{ACE}$ is defined as the sum of the squared maximum wind speeds of the cyclones present, at 6-h intervals, for the time interval considered, for instance, in a year. Given its dependence on the square of the wind speed, ACE is dominated by the intense typhoons. Camargo and Sobel (2005) have shown that ACE has a strong relationship with ENSO: it attains large values in EN

TABLE 2. NTC, number of landfalls (NLF), and percentage of landfall (PLF), given for each cluster and for all TCs (ALL) in El Niño, La Niña, and neutral years. Clusters whose landfall percentages are significantly different between the two ENSO phases are in italics. Clusters whose landfall percentage is significantly different in a specific ENSO phase from that of all TCs are marked in boldface.

\begin{tabular}{|c|c|c|c|c|c|c|c|c|c|}
\hline \multirow[b]{2}{*}{ Cluster } & \multicolumn{3}{|c|}{ El Niño } & \multicolumn{3}{|c|}{ La Niña } & \multicolumn{3}{|c|}{ Neutral } \\
\hline & NTC & NLF & PLF & NTC & NLF & PLF & NTC & NLF & PLF \\
\hline A & 52 & 30 & $58 \%$ & 89 & 47 & $53 \%$ & 165 & 111 & $67 \%$ \\
\hline $\mathrm{B}$ & 62 & 53 & $85 \%$ & 73 & 61 & $84 \%$ & 145 & 124 & $86 \%$ \\
\hline $\mathrm{C}$ & 56 & 4 & $7 \%$ & 45 & 2 & $4 \%$ & 134 & 11 & $8 \%$ \\
\hline $\mathrm{D}$ & 38 & 28 & $74 \%$ & 54 & 36 & $67 \%$ & 86 & 65 & $76 \%$ \\
\hline $\mathrm{E}$ & 53 & 22 & $42 \%$ & 20 & 3 & $15 \%$ & 103 & 31 & $30 \%$ \\
\hline $\mathrm{F}$ & 30 & 18 & $60 \%$ & 26 & 16 & $62 \%$ & 56 & 37 & $66 \%$ \\
\hline G & 53 & 7 & $13 \%$ & 5 & 1 & $20 \%$ & 48 & 8 & $17 \%$ \\
\hline ALL & 344 & 162 & $47 \%$ & 312 & 166 & $53 \%$ & 737 & 387 & $\mathbf{5 2} \%$ \\
\hline
\end{tabular}


TABLE 3. Pearson's correlations between NTC and the Niño-3.4 index, for each cluster and for all TCs. The correlations are given over the 1950-2002 period, for several 3-month "seasons," as well as one 4-month and one 6-month season, and the whole year; for the cases of JJASON and the whole year, the Niño-3.4 index over JASO was used. We show only seasons with at least one correlation in one of the clusters being significant at the $95 \%$ level (in boldface). The correlations marked in boldface are also significant at this level in the 1970-2002 period and/or using Spearman's rank correlation in both periods.

\begin{tabular}{|c|c|c|c|c|c|c|c|c|}
\hline \multirow[b]{2}{*}{ Season } & \multicolumn{7}{|c|}{ Clusters } & \multirow[b]{2}{*}{ All TCs } \\
\hline & A & B & $\mathrm{C}$ & $\mathrm{D}$ & $\mathrm{E}$ & $\mathrm{F}$ & G & \\
\hline MJJ & $-\mathbf{0 . 3 0}$ & 0.02 & 0.03 & 0.10 & 0.41 & 0.08 & 0.47 & 0.21 \\
\hline JJA & -0.37 & 0.12 & -0.23 & 0.20 & 0.52 & 0.03 & 0.48 & 0.20 \\
\hline JAS & -0.62 & 0.13 & -0.10 & 0.23 & 0.41 & 0.02 & 0.44 & 0.06 \\
\hline ASO & -0.53 & -0.07 & 0.05 & -0.22 & 0.31 & -0.04 & 0.36 & -0.11 \\
\hline SON & -0.41 & -0.23 & 0.22 & -0.39 & 0.13 & -0.06 & 0.44 & -0.15 \\
\hline OND & -0.17 & -0.33 & 0.18 & -0.45 & 0.01 & -0.07 & 0.53 & -0.15 \\
\hline NDJ & -0.19 & -0.37 & 0.18 & -0.42 & -0.04 & -0.12 & 0.54 & -0.20 \\
\hline JASO & -0.66 & -0.06 & 0.01 & -0.05 & 0.39 & -0.02 & 0.44 & -0.02 \\
\hline JJASON & -0.53 & -0.09 & 0.01 & -0.13 & 0.42 & -0.01 & 0.52 & 0.06 \\
\hline Year & -0.48 & -0.09 & 0.03 & -0.21 & 0.40 & 0.15 & 0.61 & 0.18 \\
\hline
\end{tabular}

years and low values in LN years; this relationship reflects the occurrence of more intense cyclones in EN years.

Figure 12 shows the mean value of ACE in each cluster for different ENSO states. Clusters E and G have very high values of ACE in EN years, compared with LN or neutral years. This is still the case for cluster C, although somewhat less strikingly, while clusters A
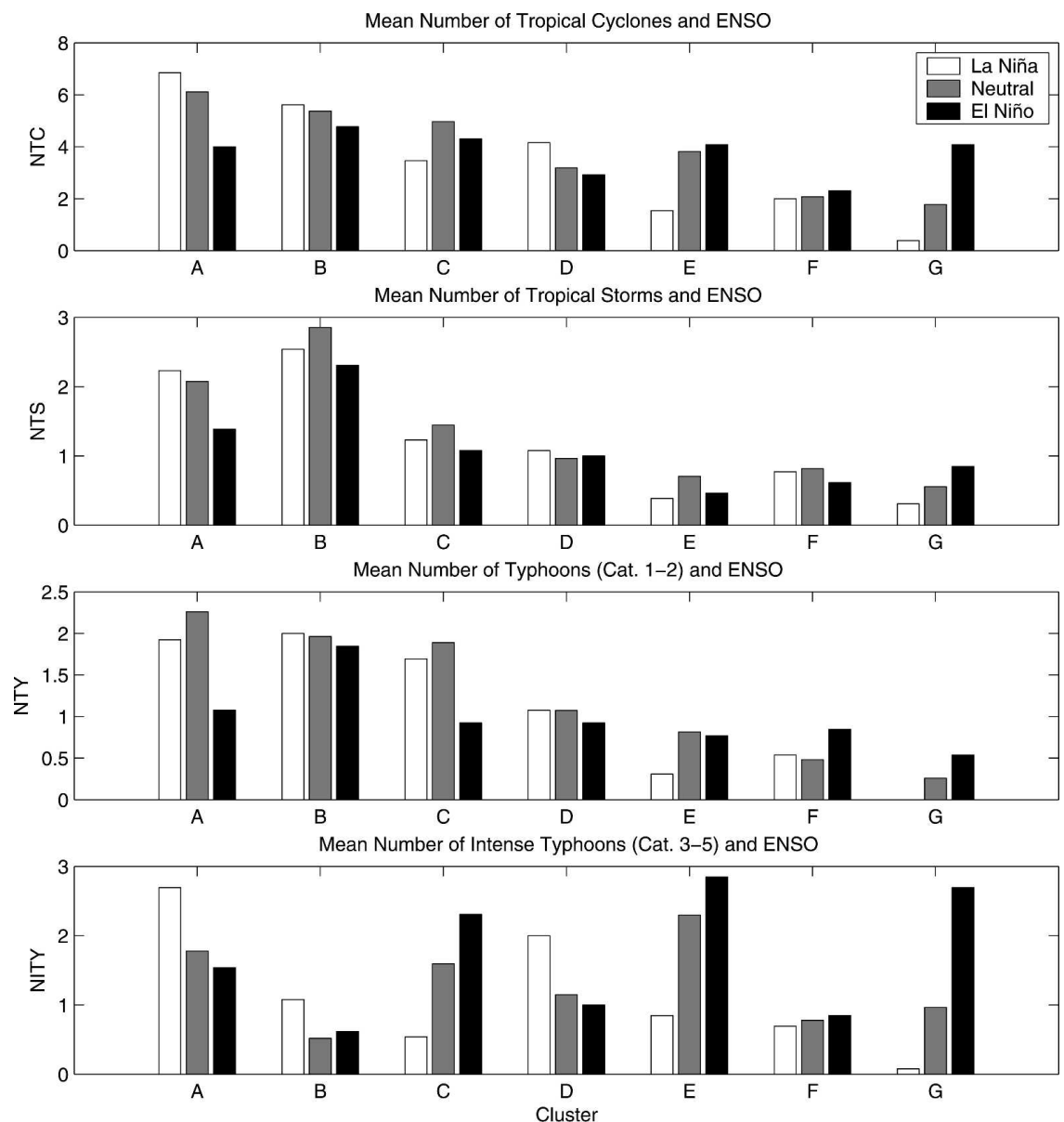

FIG. 11. Mean NTC, number of tropical storms (NTS), number of typhoons (NTY), and number of intense typhoons (NITY) per cluster in La Niña, neutral, and El Niño years. 


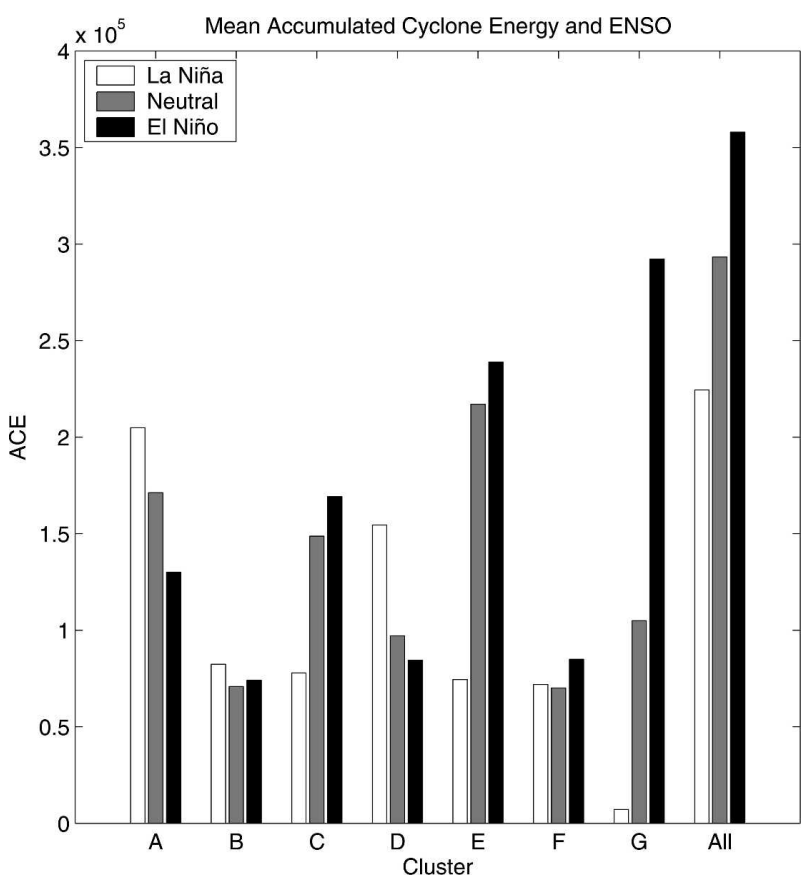

FIG. 12. Mean ACE per year in La Niña, neutral, and El Niño years, in $\mathrm{m}^{2} \mathrm{~s}^{-2}$, per cluster and for all TCs, in La Niña, neutral, and El Niño years. The values of ACE for all TCs were divided by 3 , in order to fit on the same scale as the ACE per cluster.

and D have smaller ACE values in EN years. This small ACE value is due to the smaller number of cyclones in EN years for clusters A and D (see Fig. 10). These results are reflected in the correlations between $\mathrm{ACE}$ and Niño-3.4 in Table 4. ACE values per year in clusters $\mathrm{E}$ and $\mathrm{G}$ have a positive correlation with Niño-3.4, while those in cluster A are negative. The positive correlations are responsible for the significant correlation between ACE per year with the Niño-3.4 index for all TCs (Camargo and Sobel 2005).

It follows that the higher number of ITYs found by Camargo and Sobel (2005) in the WNP in EN years does not occur over all TCs but is restricted to a few clusters, specifically clusters E and G. Interestingly, other clusters (A and D) tend to have smaller values of $\mathrm{ACE}$ in EN years, but the total ACE is dominated by clusters $\mathrm{E}$ and $\mathrm{G}$.

\section{b. Tracks, track density, landfall, and ENSO}

The tracks of WNP cyclones in EN and LN years for clusters A, E, and G are shown in Fig. 13. Cluster A has more TCs in LN years (89) than EN years (52), while clusters $\mathrm{E}(55 \mathrm{EN}, 20 \mathrm{LN})$ and $\mathrm{G}(53 \mathrm{EN}, 5 \mathrm{LN})$ have many more in EN years. The lack of TCs in cluster $\mathrm{G}$ in La Niña years is striking. Cluster D (not shown) tends to have more TCs in $\mathrm{LN}$ years, but the difference is less striking (54 LN, $38 \mathrm{EN}$ ). The other clusters (not shown) either tend to have more TCs in EN years, but the differences are only of the order of $10 \%-20 \%$.

The track density is defined as the number of TCs passing over a grid box of $2^{\circ}$ latitude by $2^{\circ}$ longitude. The difference in track density between EN and LN years is shown in Fig. 14. When all tracks are considered, there is an overall tendency for higher track densities in EN years, with a maximum difference in densities centered near $150^{\circ} \mathrm{E}$, and a negative minimum in the South China Sea. This reflects the known west-toeast shift of TC tracks during ENSO years (Wang and Chan 2002; Camargo and Sobel 2005). The track density difference between warm and cold ENSO events, stratified by cluster, shows a predominance of higher densities for EN years in clusters C, E, F, and G. The

TABLE 4. Pearson's correlations between ACE per year and Niño-3.4 index, for each cluster and for all TCs. Same treatment as in Table 3, with ACE here replacing NTC there. The correlations marked in boldface are significant at the $95 \%$ level and also using Spearman's rank correlation.

\begin{tabular}{|c|c|c|c|c|c|c|c|c|}
\hline \multirow[b]{2}{*}{ Season } & \multicolumn{7}{|c|}{ Clusters } & \multirow[b]{2}{*}{ All TCs } \\
\hline & A & B & $\mathrm{C}$ & $\mathrm{D}$ & $\mathrm{E}$ & $\mathrm{F}$ & G & \\
\hline MAM & -0.21 & -0.45 & -0.14 & -0.19 & -0.32 & 0.07 & -0.02 & -0.30 \\
\hline MJJ & -0.28 & -0.16 & 0.04 & -0.10 & 0.36 & 0.25 & 0.44 & 0.39 \\
\hline JJA & -0.42 & -0.01 & -0.02 & 0.21 & 0.67 & 0.25 & 0.59 & 0.68 \\
\hline JAS & -0.50 & 0.13 & 0.07 & 0.30 & 0.59 & 0.15 & 0.65 & 0.66 \\
\hline ASO & -0.44 & -0.01 & 0.19 & -0.14 & 0.43 & -0.12 & 0.48 & 0.45 \\
\hline SON & -0.30 & -0.08 & 0.31 & -0.39 & 0.11 & -0.14 & 0.51 & 0.29 \\
\hline OND & -0.27 & -0.24 & 0.25 & -0.42 & -0.01 & -0.02 & 0.58 & 0.35 \\
\hline NDJ & -0.25 & -0.25 & 0.24 & -0.39 & 0.01 & -0.10 & 0.59 & 0.28 \\
\hline DJF & -0.04 & 0.33 & 0.00 & -0.18 & -0.14 & 0.22 & 0.55 & 0.56 \\
\hline JASO & -0.57 & -0.05 & 0.17 & -0.14 & 0.57 & -0.10 & 0.64 & 0.53 \\
\hline JJASON & -0.51 & -0.02 & 0.18 & -0.28 & 0.48 & -0.01 & 0.64 & 0.60 \\
\hline Year & -0.47 & -0.05 & 0.20 & -0.33 & 0.44 & 0.27 & 0.67 & 0.69 \\
\hline
\end{tabular}



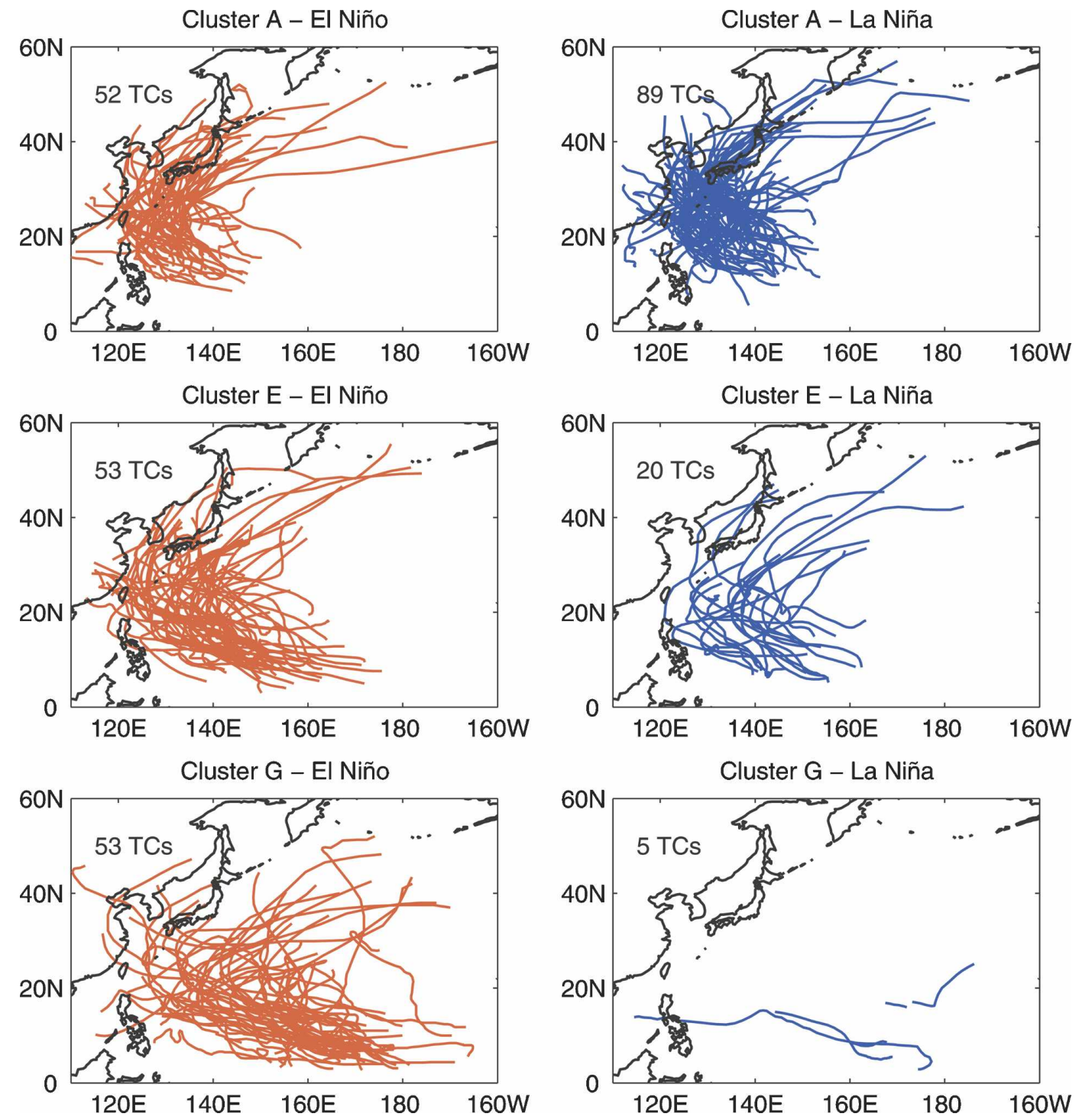

FIG. 13. Cyclone tracks in (left) El Niño years (red) and (right) La Niña years (blue) for clusters A, E, and G.

track density difference in clusters A and D shows a negative pattern, reflecting the greater number of tracks in LN years. Cluster B has a bimodal pattern, with a maximum northwest of the Philippines (EN) and a minimum south of that (LN); this pattern represents a northward shift in the track density from LN to EN years.

Table 2 shows NTC, the number of landfalling TCs, and percentage of landfall per cluster, according to ENSO phase. In neutral years landfall percentages for all the clusters are different from all the TCs taken together. In these years, on average, about one TC in two hits land; the percentage is much higher in clusters $\mathrm{A}, \mathrm{B}, \mathrm{D}$, and F, while it is much lower in clusters $\mathrm{C}, \mathrm{E}$, and G. There is no statistically significant difference in landfall percentage between ENSO phases when the full basin is considered. The same is true for the clusters, with the exception of cluster A (LN and neutral) and $\mathrm{E}$ (EN and LN), for which the difference is statistically significant. When considering EN years, the clusters with landfall percentages, whose difference from all TCs is statistically significant, are clusters B, C, D, and $\mathrm{G}$; in $\mathrm{LN}$ years, this difference is significant for clusters B, C, and E.

\section{c. Madden-Julian oscillation}

The MJO (Madden and Julian 1972) is notably weaker during boreal summer than in boreal winter 

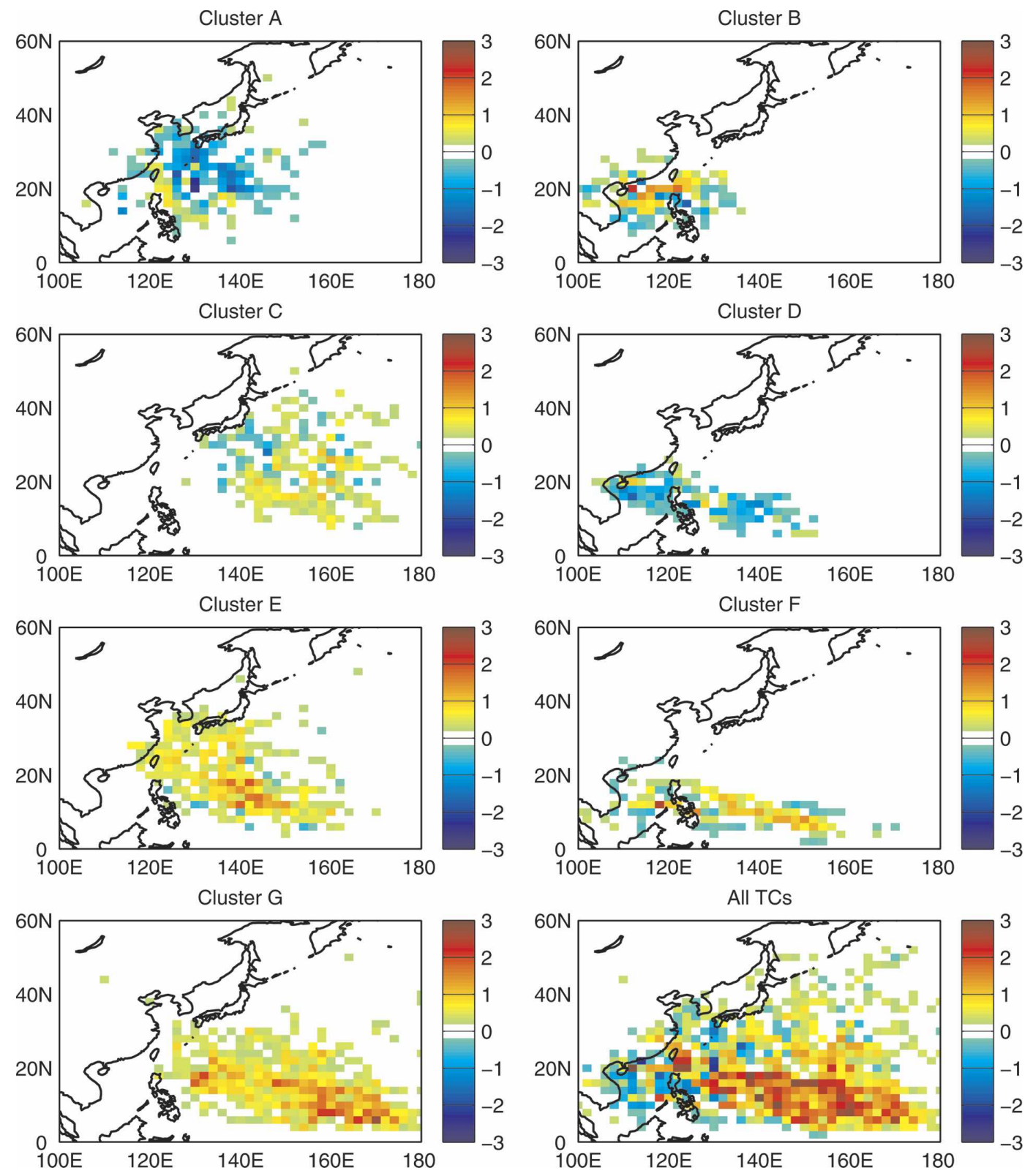

FIG. 14. Track density difference between El Niño and La Niña years for each cluster and all TCs; the resolution is $2 \mathrm{deg} \times 2 \mathrm{deg}$.

(e.g., Wang and Rui 1990; Ghil and Mo 1991) and is characterized by northward propagation in the Indian summer monsoon region and in the WNP (KemballCook and Wang 2001), sometimes referred to as the tropical intraseasonal oscillation (Chao 1987; Rui and Wang 1990). The MJO is known to influence TC activity over the WNP: when the MJO is active over the WNP or the Maritime Continent; the tendency for cyclogenesis in the region is higher (Liebmann et al. 1994; Sobel and Maloney 2000).
We have stratified in Fig. 15 the genesis of TCs according to the eight phases of the MJO, as defined by Wheeler and Hendon (2004), for all TCs (Fig. 15a), and for each cluster (Fig. 15b). There are more TCs generated over the entire WNP when the MJO is active in the Maritime Continent (phases 4 and 5) and the eastern WNP (phase 6) [see Figs. 5 and 8 of Wheeler and Hendon (2004) and Fig. 16 of Ghil and Mo (1991), for the OLR patterns associated with each phase], with fewer occurring in the other MJO phases (Fig. 15a). We cal- 
(a)

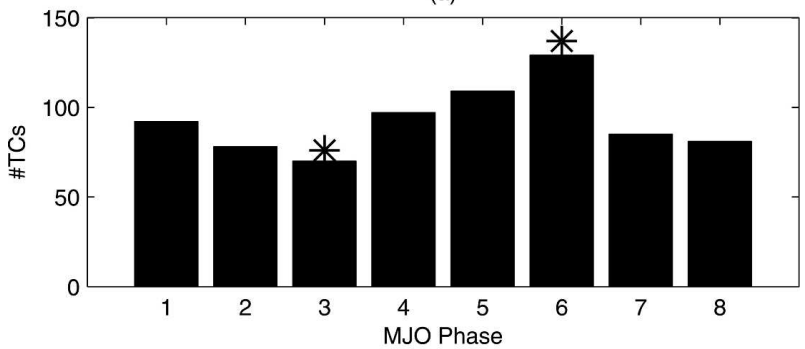

(b)

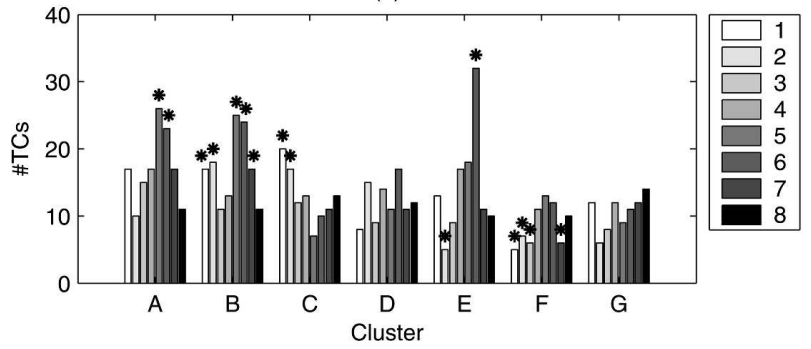

FIG. 15. Number of TCs that arise in each MJO phase in the period 1974-2002: (a) all TCs and (b) for each cluster. Asterisks indicate statistical significance at the $99 \%$ level.

culated the statistical significance of the NTCs in each MJO phase using a bootstrap method that assigns randomly to each TC an MJO phase for 1000 trials. The peak in NTC for phase 6 and the minimum for phase 3 (Indian Ocean) are statistically significant at the 99\% level.

The statistical significance in Fig. 15b was also calculated using a bootstrap method, assigning random MJO phases to the TCs in each cluster. In the dominant clusters (A and $\mathrm{B}$ ) the peak on phases 5 (Maritime Continent) and 6 (eastern WNP) are statistically significant at the $99 \%$ level. This results in the peak of the total NTC during those phases. Cluster E has a large peak in phase 6 (WNP), while other peaks in various clusters, as well as minima that indicate lack of TC formation in the corresponding MJO phase, also appear as statistically significant.

The location of the composite OLR anomalies (Fig. 5) and low-level westerly wind anomalies (Fig. 4) near the equator for cluster $\mathrm{E}$ are somewhat similar to the MJO pattern of phase 6 shown in Fig. 8 of Wheeler and Hendon (2004) and the composite [panel (f)] in Fig. 5 of Kemball-Cook and Wang (2001), although our TCbased composites are for the entire year, while those of the previous authors are MJO based and for DJF or ASO, respectively. The location of OLR and surface wind anomalies for cluster A are also similar to the composite [panel (g)] in Fig. 5 of Kemball-Cook and Wang (2001).

\section{Concluding remarks}

\section{a. Summary}

In this two-part paper, a new clustering technique based on both shape and location of cyclone trajectories was applied to the western North Pacific (WNP) TC tracks. The general properties of these clusters were presented in Part I. In the present paper, we have investigated the large-scale patterns associated with each of the clusters, and the influence of the MJO and ENSO phases on the clusters' properties.

The large-scale patterns in each cluster are found to be physically consistent in all the fields examined here. The steering winds are more zonal in the straightmoving clusters, while there is a larger meridional component in the recurving ones (Fig. 1). The subtropical high tends to be stronger, with an extension over the Asian continent for the straight-moving tracks (Fig. 2). Higher values of vertical wind shear accompany the straight-moving tracks, compared to the recurving track clusters (Fig. 8).

The OLR minima and low-level vorticity maxima composited according to first TC positions are collocated with the genesis distribution maxima in each cluster (Figs. 5 and 4). The OLR maxima at the maximum intensity (not shown) occur farther to the northwest, following the cyclones trajectories. Anticyclonic lowlevel vorticity anomalies (Fig. 4) surround the vorticity maxima, typical of Rossby wave dispersion. In some clusters (A and C) these features are more pronounced than in others, indicating a preconditioning for formation of TCs in the wake of an existing TC.

The clusters can also be characterized in terms of different configurations of the monsoon trough, extending into the WNP (Fig. 3). Certain clusters (A, B, and $\mathrm{E}$ ) occur more often during the phase in which the MJO is over the Maritime Continent and WNP (Fig. 15). The OLR and surface wind anomalies composites of clusters A and E have similarities with MJO patterns identified in previous studies (Kemball-Cook and Wang 2001; Wheeler and Hendon 2004).

While some clusters exhibit a strong influence of the ENSO phase, others do not. Two of the clusters ( $\mathrm{E}$ and G) are typical of EN events (Figs. 12 and 14), with first position located nearer the date line and more equatorward than other clusters (Figs. 1 and 13). In contrast, cluster A, the most highly populated cluster, tends to occur more often during LN events (Figs. 12-14). The TCs in clusters $\mathrm{E}$ and $\mathrm{G}$ are more intense than TCs in cluster A (Fig. 11); therefore the intensity of the complete set of TCs is dominated by the leading clusters and there is a strong relationship between accumulated 
cyclone energy (ACE) and ENSO (Fig. 12). The relationship between intensity and clusters could be useful for tropical cyclones forecasts.

We have examined the difference in track density between warm and cold events, for those clusters that are affected by the ENSO phase. This difference is responsible for the shift of track types according to ENSO events discussed in previous studies (Wang and Chan 2002; Wu and Wang 2004). By isolating the ENSO effects in specific clusters, the ENSO influence can be more easily discerned.

\section{b. Discussion}

Several previous authors have studied the effect of the large-scale environment on TC activity over the WNP, highlighting the role of the monsoon trough and the subtropical ridge (Harr and Elsberry 1991; Lander 1994b, 1996; Harr and Elsberry 1995a,b; Holland 1995; Briegel and Frank 1997; Ritchie and Holland 1999; Liu and Chan 2002). Our clustering results are consistent with these studies, while shedding additional light on the mechanisms involved. Stratifying the analysis by TC cluster helps delineate the differences in the two major large-scale features that accompany the different TC track types identified by our analysis. The important role of the TCs themselves in these WNP variations of these "monsoonal" features is strongly suggested by the collocation, within each cluster, between the distribution of TC genesis positions and the composite circulation anomalies.

TC activity thus contributes to a westward extension of the east Asian monsoon into the WNP. The typhoon season in late summer and fall corresponds to the seasonal migration of monsoon circulation from East Asia in boreal summer toward Australasia in boreal winter. The cluster-stratified seasonal evolution (Fig. 10 of Part I) represents this approximately as A-B-C-E-D-F, that is, more or less in order of decreasing size of the clusters; the shift is from northwest to southeast and generally from recurving to straight-moving tracks. The clusters clearly illustrate how this extension is modulated, intraseasonally by the MJO, and interannually by ENSO.

The identification of the typical large-scale anomalies and related track and TC properties in each cluster could provide useful tools to forecasters. Identifying fairly early in its development which cluster a TC belongs to, based on its genesis location and a few subsequent, 6-hourly positions, could help forecast the most probable track type and landfall region of that TC.

Chan (1994) discussed statistical forecasts of TCs with different track types based on the zonal wind patterns in the months prior to the typhoon season. Sea- sonal SST forecasts could be used to assign higher probabilities to certain clusters, especially for the ENSOinfluenced clusters.

Similarly, the cluster analysis presented here could be used to assess the impact of global warming on TC activity from model scenario experiments. Understanding the long-term trends in tropical cyclone activity and tracks is essential for a better assessment of possible changes due to global warming (Chan and Liu 2004; Knutson and Tuleya 2004; Walsh 2004; Wu and Wang 2004; Emanuel 2005; Pielke et al. 2005; Trenberth 2005; Webster et al. 2005).

Acknowledgments. S. J. Camargo would like to thank Anthony G. Barnston, Michael K. Tippett, and Lisa Goddard for suggestions on statistical significance of the composites and Adam $\mathrm{H}$. Sobel for valuable discussions. This work was support in part by NOAA through a block grant to the International Research Institute for Climate and Society (S. J. Camargo and A. W. Robertson), Department of Energy Grant DE-FG02ER6413 (M. Ghil and A. W. Robertson), and the National Science Foundation under Grants SCI-0225642 and IIS0431085 (S. J. Gaffney and P. Smyth). MG also wishes to acknowledge the European Commission's Project No. 12975 (NEST), "Extreme Events: Causes and Consequences (E2-C2)."

\section{APPENDIX}

\section{Description of Significance Test for Composites}

The Monte Carlo test for each cluster was computed as follows: 1) the difference between the all-TCs composite and the specific cluster composite over the time interval under consideration is calculated; 2) the same number of TCs used in the specific composite is picked at random from all the TCs for the same time interval; 3 ) the difference between this random composite and the all-TCs composite is computed; 4) steps 2 and 3 are repeated 500 times; 5) the highest and lowest $2.5 \%$ values at each grid point from the difference between the cluster composites and the all-TCs composite at that grid point are defined as the top and bottom thresholds, respectively; and 6) cluster composites above the top and below the bottom thresholds are considered significant.

For the all-TCs composites, the Monte Carlo test was performed as follows: 1) the cumulative distribution function (cdf) of the number of cyclones per day, summed over all the years in the record is computed; 2) a date within the year is obtained using a uniform random number generator; 3 ) the cdf of the TC's seasonal 
cycle is then used to obtain a random date weighted by this cycle; 4) a composite is made with the same number of dates (random TC first positions) used in the all-TCs composite; 5) step 4 is repeated 500 times; 6) the highest and lowest $2.5 \%$ values at each grid point of the 500 random composites are defined as the top and bottom thresholds, respectively; and 7) if the all-TCs composite value at that location lies outside these two thresholds, it is considered significant.

\section{REFERENCES}

Aref, H., 1983: Integrable, chaotic, and turbulent vortex motion in two-dimensional flow. Annu. Rev. Fluid Mech., 15, 345-389.

Atkinson, G., 1977: Proposed system for near real time monitoring of global tropical circulation and weather patterns. Preprints, 11th Conf. on Hurricanes and Tropical Meteorology, Miami Beach, FL, Amer. Meteor. Soc., 645-652.

Barnston, A. G., M. Chelliah, and S. B. Goldenberg, 1997: Documentation of a highly ENSO-related SST region in the equatorial Pacific. Atmos.-Ocean, 35, 367-383.

Bell, G. D., and Coauthors, 2000: Climate assessment for 1999. Bull. Amer. Meteor. Soc., 81, S1-S50.

Brand, S., 1971: The effects on a tropical cyclone of cooler surface waters due to upwelling and mixing produced by a prior tropical cyclone. J. Appl. Meteor., 10, 865-874.

Briegel, L. M., and W. M. Frank, 1997: Large-scale influences on tropical cyclogenesis in the western North Pacific. Mon. Wea. Rev., 125, 1397-1413.

Camargo, S. J., and A. H. Sobel, 2005: Western North Pacific tropical cyclone intensity and ENSO. J. Climate, 18, 29963006.

, A. W. Robertson, S. J. Gaffney, P. Smyth, and M. Ghil, 2007: Cluster analysis of typhoon tracks. Part I: General properties. J. Climate, 20, 3635-3653.

Carr, L. E., III, and R. L. Elsberry, 1990: Observational evidence for predictions of tropical cyclone propagation relative to steering. J. Atmos. Sci., 47, 542-546.

— tropical cyclone track changes. Mon. Wea. Rev., 123, 265-289.

Chan, J. C. L., 1985: Tropical cyclone activity in the northwest Pacific in relation to the El Niño/Southern Oscillation phenomenon. Mon. Wea. Rev., 113, 599-606.

- 1994: Prediction of the interannual variations of tropical cyclone movement over regions of the western North Pacific. Int. J. Climatol., 14, 527-538.

- 1995: Prediction of annual tropical cyclone activity over the western North Pacific and the South China Sea. Int. J. Climatol., 15, 1011-1019.

— 2000: Tropical cyclone activity over the western North Pacific associated with El Niño and La Niña events. J. Climate, 13, 2960-2972.

- 2005: The physics of tropical cyclone motion. Annu. Rev. Fluid Mech., 37, 99-128.

— rounding flow relationships. Mon. Wea. Rev., 110, 1354-1374.

_ Guandong province of China during the period 1470-1931. Int. J. Climatol., 20, 183-190.

—, and K. S. Liu, 2004: Global warming and western North
Pacific typhoon activity from an observational perspective. $J$. Climate, 17, 4590-4602.

Chao, W. C., 1987: On the origin of the tropical intraseasonal oscillation. J. Atmos. Sci., 44, 1940-1949.

Chen, T.-C., S.-P. Weng, N. Yamazaki, and S. Kiehne, 1998: Interannual variation in the tropical cyclone activity over the western North Pacific. Mon. Wea. Rev., 126, 1080-1090.

- , S.-Y. Wang, M.-C. Yen, and W. A. G. Jr., 2004: Role of the monsoon gyre in the interannual variation of the tropical cyclone formation over the western North Pacific. Wea. Forecasting, 19, 776-785.

Chia, H. H., and C. F. Ropelewski, 2002: The interannual variability in the genesis location of tropical cyclones in the northwest Pacific. J. Climate, 15, 2934-2944.

Chu, P.-S., 2002: Large-scale circulation features associated with decadal variations of tropical cyclone activity over the central North Pacific. J. Climate, 15, 2678-2689.

_ , and J. Wang, 1997: Tropical cyclone occurrences in the vicinity of Hawaii: Are the differences between El Niño and non-El Niño years significant? J. Climate, 10, 2683-2689.

Clark, J. D., and P.-S. Chu, 2002: Interannual variation of tropical cyclone activity over the central North Pacific. J. Meteor. Soc. Japan, 80, 403-418.

CPC, cited 2007: Monthly atmospheric and SST indices. [Available online at http://www.cpc.noaa.gov/products/data/indices/.]

Dickinson, M., and J. Molinari, 2002: Mixed Rossby-gravity waves and western Pacific tropical cyclogenesis. Part I: Synoptic evolution. J. Atmos. Sci., 59, 2183-2196.

Elsner, J. B., and K. B. Liu, 2003: Examining the ENSO-typhoon hypothesis. Climate Res., 25, 43-54.

Emanuel, K. A., 1991: The theory of hurricanes. Annu. Rev. Fluid Mech., 23, 179-196.

, 1999: Thermodynamic control of hurricane intensity. $\mathrm{Na}$ ture, 401, 665-669.

— 2005: Increasing destructiveness of tropical cyclones over the past 30 years. Nature, 436, 686-688.

Ferreira, R. N., and W. H. Schubert, 1999: The role of tropical cyclones in the formation of tropical upper-tropospheric troughs. J. Atmos. Sci., 56, 2891-2907.

Fiorino, M. J., and R. L. Elsberry, 1989: The role of vortex structure in tropical cyclone motion. J. Atmos. Sci., 46, 975-990.

Frank, W. M., 1982: Large-scale characteristics of tropical cyclones. Mon. Wea. Rev., 110, 572-586.

Franklin, J. L., S. E. Feuer, J. Kaplan, and S. D. Aberson, 1996: Tropical cyclone motion and surrounding flow relationships: Searching for beta gyres in omega dropwindsond datasets. Mon. Wea. Rev., 124, 64-84.

Gaffney, S. J., 2004: Probabilistic curve-aligned clustering and prediction with regression mixture models. Ph.D. thesis, University of California, Irvine, $281 \mathrm{pp}$. [Available online at $\mathrm{http}$ ://ftp.ics.uci.edu/pub/sgaffney/outgoing/sgaffney_thesis. pdf.]

, A. W. Robertson, P. Smyth, S. J. Camargo, and M. Ghil, 2007: Probabilistic clustering of extratropical cyclones using regression mixture models. Climate Dyn., in press.

Ghil, M., and K.-C. Mo, 1991: Intraseasonal oscillations in the global atmosphere. Part I: Northern Hemisphere and tropics. J. Atmos. Sci., 48, 752-779.

Goddard, L., and M. Dilley, 2005: El Niño: Catastrophe or opportunity? J. Climate, 18, 651-665.

Harr, P. A., and R. L. Elsberry, 1991: Tropical cyclone track characteristics as a function of large-scale circulation anomalies. Mon. Wea. Rev., 119, 1448-1468. 
$\longrightarrow$, and 1995a: Large-scale circulation variability over the tropical western North Pacific. Part I: Spatial patterns and tropical cyclone characteristics. Mon. Wea. Rev., 123, 12251246.

— tropical western North Pacific. Part II: Persistence and transition characteristics. Mon. Wea. Rev., 123, 1247-1268.

Ho, C.-H., J.-J. Baik, J.-H. Kim, and D.-Y. Gong, 2004: Interdecadal changes in summertime typhoon tracks. J. Climate, 17, $1767-1776$.

Holland, G. J., 1995: Scale interaction in the western Pacific monsoon. Meteor. Atmos. Sci., 56, 57-79.

Ide, K., and M. Ghil, 1997a: Extended Kalman filtering for vortex systems. Part I: Methodology and point vortices. Dyn. Atmos. Oceans, 27, 301-332.

— tems. Part II: Rankine vortices and observing-system design. Dyn. Atmos. Oceans, 27, 333-350.

Itoh, H., and M. Ghil, 1988: The generation mechanism of mixed Rossby-gravity waves in the equatorial troposphere. J. Atmos. Sci., 45, 585-604.

Joint Typhoon Warning Center, cited 2007: JTWC (Joint Typhoon Warning Center) best track dataset. [Available online at https://metoc.npmoc.navy.mil/jtwc/best-tracks/.]

Kalnay, E., and Coauthors, 1996: The NCEP/NCAR 40-Year Reanalysis Project. Bull. Amer. Meteor. Soc., 77, 437-441.

Kemball-Cook, S., and B. Wang, 2001: Equatorial waves and airsea interaction in the boreal summer intraseasonal oscillation. J. Climate, 14, 2923-2942.

Knutson, T. R., and R. E. Tuleya, 2004: Impact of $\mathrm{CO}_{2}$-induced warming on simulated hurricane intensity and precipitation: Sensitivity to choice of climate model and convective parameterization. J. Climate, 17, 3477-3495.

Kumar, V., and R. Krishnan, 2005: On the association between the Indian summer monsoon and the tropical cyclone activity over northwest Pacific. Curr. Sci., 88, 602-612.

Kuo, H.-C., J.-H. Chen, R. T. Williams, and C.-P. Chang, 2001: Rossby waves in zonally opposing mean flow: Behavior in the Northwest Pacific summer monsoon. J. Atmos. Sci., 58, 10351050.

Lander, M. A., 1994a: An exploratory analysis of the relationship between tropical storm formation in the western North Pacific and ENSO. Mon. Wea. Rev., 122, 636-651.

— 1994b: Description of a monsoon gyre and its effects on the tropical cyclones in the western North Pacific during August 1991. Wea. Forecasting, 9, 640-654.

_- 1996: Specific tropical cyclone tracks and unusual tropical cyclone motions associated with a reverse-oriented monsoon trough in the western North Pacific. Wea. Forecasting, 11, $170-186$.

Lau, K.-H., and N.-C. Lau, 1990: Observed structure and propagation characteristics of tropical summertime synoptic scale disturbances. Mon. Wea. Rev., 118, 1888-1913.

Li, T., B. Fu, X. Ge, B. Wang, and M. Peng, 2003: Satellite data analysis and numerical simulation of tropical cyclone formation. Geophys. Res. Lett., 30, 2122, doi:10.1029/2003GL018556.

Liebmann, B., and H. H. Hendon, 1990: Synoptic-scale disturbances near the equator. J. Atmos. Sci., 47, 1463-1479.

— , and C. A. Smith, 1996: Description of a complete (interpolated) outgoing longwave radiation dataset. Bull. Amer. Meteor. Soc., 77, 1275-1277.

— , H. H. Hendon, and J. D. Glick, 1994: The relationship between tropical cyclones of the western Pacific and Indian oceans and the Madden-Julian oscillation. J. Meteor. Soc. Japan, 72, 401-411.

Lin, I.-I., W. T. Liu, C.-C. Wu, J. C. H. Chiang, and C.-H. Sui, 2003: Satellite observations of modulation of surface winds by typhoon-induced upper ocean cooling. Geophys. Res. Lett., 30, 1131, doi:10.1029/2002GL015674.

Liu, K. S., and J. C. L. Chan, 2002: Synoptic flow patterns associated with small and large tropical cyclones over the western North Pacific. Mon. Wea. Rev., 130, 2134-2142.

Madden, R. A., and P. R. Julian, 1972: Description of global circulation cells in the Tropics with a $40-45$ day period. J. Atmos. Sci., 29, 1109-1123.

Mason, S. J., and L. Goddard, 2001: Probabilistic precipitation anomalies associated with ENSO. Bull. Amer. Meteor. Soc., 82, 619-638.

Montgomery, M. T., and B. F. Farrell, 1993: Tropical cyclone formation. J. Atmos. Sci., 50, 285-310.

Pan, Y. H., 1982: The effect of the thermal state of equatorial eastern Pacific on the frequency of typhoon over the western Pacific (in Chinese with English abstract). Acta Meteor. Sin., 40, 24-34.

Pielke, R. A., Jr., C. Landsea, M. Mayfield, J. Laver, and R. Pasch, 2005: Hurricanes and global warming. Bull. Amer. Meteor. Soc., 86, 1571-1575.

Rasmusson, E. M., and T. H. Carpenter, 1982: Variations in tropical sea surface temperature and surface wind fields associated with the Southern Oscillation/El Niño. Mon. Wea. Rev., 110, 354-384.

Reed, R. J., and E. E. Recker, 1971: Structure and properties of synoptic-scale wave disturbances in the equatorial western Pacific. J. Atmos. Sci., 28, 1117-1133.

Reynolds, R. W., N. A. Rayner, T. M. Smith, D. C. Stokes, and W. Wang, 2002: An improved in situ and satellite SST analysis for climate. J. Climate, 15, 1609-1625.

Ritchie, E. R., and G. J. Holland, 1999: Large-scale patterns associated with tropical cyclogenesis in the western Pacific. Mon. Wea. Rev., 127, 2027-2043.

Ropelewski, C. F., and M. S. Halpern, 1987: Global and regional scale precipitation patterns associated with the El Niño/ Southern Oscillation. Mon. Wea. Rev., 115, 1606-1626.

Rui, H., and B. Wang, 1990: Development characteristics and dynamic structure of the tropical intraseasonal convection anomalies. J. Atmos. Sci., 47, 357-379.

Sadler, J. C., 1978: Mid-season typhoon development and intensity changes and the tropical upper tropospheric trough. Mon. Wea. Rev., 106, 1137-1152.

Saffir, H. S., 1977: Design and construction requirements for hurricane resistant construction. ASCE Tech. Rep. Preprint 2830, 20 pp. [Available from American Society of Civil Engineers, New York, NY 10017.]

Saunders, M. A., R. E. Chandler, C. J. Merchant, and F. P. Roberts, 2000: Atlantic hurricanes and NW Pacific typhoons: ENSO spatial impacts on occurrence and landfall. Geophys. Res. Lett., 27, 1147-1150.

Simpson, R. H., and H. Riehl, 1981: The Hurricane and Its Impact. Louisiana State University Press, 398 pp.

Sobel, A. H., and C. S. Bretherton, 1999: Development of synoptic-scale disturbances over summertime tropical northwest Pacific. J. Atmos. Sci., 56, 3106-3127. 
western North Pacific tropical cyclones. Geophys. Res. Lett., 27, 1739-1742.

—_, and S. J. Camargo, 2005: Influence of western North Pacific tropical cyclones on their environment. J. Atmos. Sci., 62, 3396-3407.

Trenberth, K. E., 1997: The definition of El Niño. Bull. Amer. Meteor. Soc., 78, 2771-2777.

- 2005: Uncertainty in hurricanes and global warming. Science, 308, 1753-1754.

von Helmholtz, H. L. F., 1867: On the integrals of the hydrodynamical equations which express vortex motions. Philos. Mag., 33, 485-512.

Walsh, K., 2004: Tropical cyclones and climate change: Unresolved issues. Climate Res., 27, 77-83.

Wang, B., and H. Rui, 1990: Synoptic climatology of transient tropical intraseasonal convection anomalies: 1975-1985. Meteor. Atmos. Phys., 44, 43-61.

, and X. Li, 1992: The beta drift of three-dimensional vortices: A numerical study. Mon. Wea. Rev., 120, 579-593.

, and J. C. L. Chan, 2002: How strong ENSO events affect tropical storm activity over the western North Pacific. J. Climate, 15, 1643-1658.
Wang, Y., and G. J. Holland, 1996: The beta drift of baroclinic vortices. Part II: Diabatic vortices. J. Atmos. Sci., 53, 33133332

Webster, P. J., G. J. Holland, J. A. Curry, and H.-R. Chang, 2005: Changes in tropical cyclone number, duration, and intensity in a warming environment. Science, 309, 1844-1846.

Wheeler, M. C., and G. N. Kiladis, 1999: Convectively coupled equatorial waves: Analysis of clouds and temperature in the wavenumber-frequency domain. J. Atmos. Sci., 56, 374-399.

_ , and H. H. Hendon, 2004: An all-season real-time multivariate MJO index: Development of an index for monitoring and prediction. Mon. Wea. Rev., 132, 1917-1932.

Wu, C.-C., and K. A. Emanuel, 1995: Potential vorticity diagnostics of hurricane movement. Part I: A case study of Hurricane Bob (1991). Mon. Wea. Rev., 123, 69-92.

Wu, L., and B. Wang, 2004: Assessing impacts of global warming on tropical cyclone tracks. J. Climate, 17, 1686-1698.

Wu, M. C., W. L. Chang, and W. M. Leung, 2004: Impacts of El Niño-Southern Oscillation events on tropical cyclone landfalling activity in the western North Pacific. J. Climate, 17, 1419-1428. 